\title{
EL CERRICO REDONDO (MONTEALEGRE DEL CASTILLO), LAS PEÑUELAS (POZO CAÑADA-CHINCHILLA) Y LA MINA DE D. RICARDO (TIRIEZ-LEZUZA): TRES YACIMIENTOS DE LA EDAD DEL BRONCE EN ALBACETE
}

\author{
JOSÉ LUIS SIMÓN GARCÍA \\ Universidad de Alicante
}

\begin{abstract}
Se estudian tres yacimientos de la Edad del Bronce en el término de Almansa (Albacete), excavados parcialmente hace muchos años. Su larga perduración, los materiales que proporcionan y los lugares donde se ubican parecen atestiguar una economía ganadera y transhumante.

This paper deals with three sites of the Bronze Age in Almansa (Albacete), partially excavated many years ago. Their survival, artifacts, and emplacements seem to show cattle raising economic activities.
\end{abstract}

\section{INTRODUCCIÓN}

La investigación sobre la Edad del Bronce en Albacete por J. Sánchez Jiménez se inicia desde sus primeros pasos en el campo de la arqueología. En 1928 se hizo cargo de la denuncia de la expoliación de Las Peñuelas, donde en 1929 realizó una excavación de «urgencia» ante la amenaza de su destrucción. En 1935 visitó El Azaralque de Agramón ante el expolio que sufría por su propietario, deteniendo la destrucción del yacimiento. En 1941 excavó el Cerrico de los Moros y en el Puntal de Conejeros. En 1942 realizó una campaña de excavación en el Cerrico Redondo, en Montealegre del Castillo, y estudió detenidamente los yacimientos prospectados por Julián Zuazo Palacios en el Término municipal de Montealegre del Castillo - Cerro de la Perdiz, Cerro de los Conejos, Cerro de Los Castillicos, Cerro del Cegarrón, Cerro de las Zorerras, etc.Durante estos años procuró recoger los materiales procedentes de la expoliación de yacimientos de la Edad del Bronce, como los del Cerro del Cegarrón (Montealegre del Castillo), la Mina de D. Ricardo o Dehesa de Caracolares (Tiriez), el Acequión (Albacete), la Morra de D. Canciano, etc. Recogió información directa sobre otros yacimientos como Sie- rra Parca (Ontur), Casa de los Arboles, la Cueva de las Descaradas (Letur), el Túmulo de Vilches (Minateda), Los Toriles, Puntal de Conejeros y Cerrico de los Moros (Tobarra) y poblados en Ojos de San Jorge, Hoyas Vacas, Pozancos, Barrax, Fontanar y la Atalaya (Caudete).

Al tiempo que se ocupaba del estudio de otros períodos, conto el ibérico y el romano, en la década de los años cuarenta publicó diversos trabajos sobre la Edad del Bronce en Albacete (SANCHEZ JIMENEZ: $1941 ; 1943 ; 1947 ; 1948$ a y b), básicos para comprender el II milenio a.C. en esta provincia.

\section{EL CERRICO REDONDO (MONTEALEGRE DEL CASTILLO)}

\section{I.1. Situación:}

El yacimiento se encuentra al $\mathrm{E}$ de la carretera local de Montealegre del Castillo a Yecla, a la altura del Km. 4'5, de la que dista unos 800 metros. Altura sobre el nivel del mar: $755 \mathrm{~m}$. Coordenadas: $38^{\circ} 45^{\prime}$ $10^{\prime \prime}$ de lat. $\mathrm{N}$ y $1^{\circ} 17^{\prime} 20^{\prime \prime}$ de long. W del meridiano de Greenwich (fig. 1:2.1 y fig. 2). 


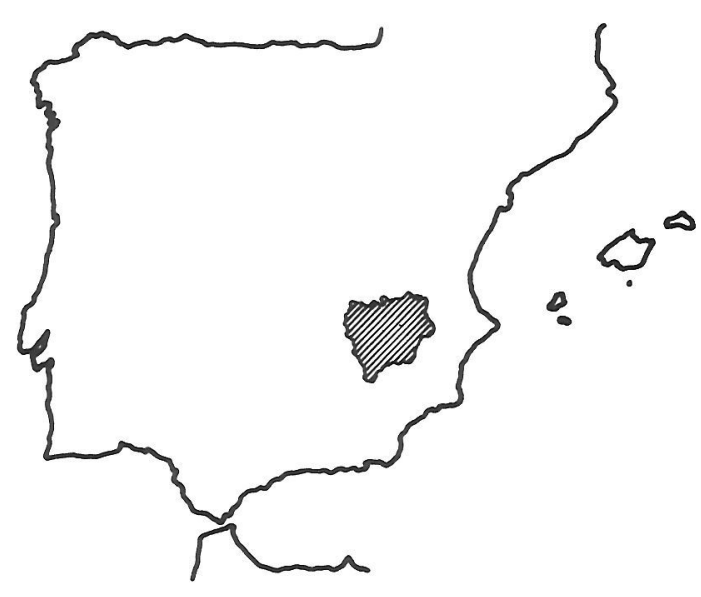

Figura 1.1.-Situación de Albacete.

\section{I.2. La excavación:}

El yacimiento fue visitado por primera vez por J. Zuazo Palacios en los años 1913-15, realizando una «exploración» o cata en lo alto del serro y señalando en sus publicaciones que se trataba, al igual que el resto de los yacimientos de este período en el Término municipal de Montealegre del Castillo, de «túmulos» funerarios con cámara y corredor. Esta visión fue recogida por J. Sánchez Jiménez el cual animado por las facilidades puestas por $\mathrm{J}$. Zuazo Palacios al costear en parte los trabajos, y las posibilidades que ofrecía el yacimiento, se decidió en 1942 a solicitar un permiso de excavación a la Comisaría General.

La excavación se realizó entre los días 20 y 29 de julio de 1942. Con anterioridad se había realizado la topografía del cerro (fig. 3:1) por el personal del Servicio de Obras y Vías de la Excma. Diputación de Albacete.

J. Sánchez Jiménez partió de la idea de que se trataba de un «túmulo» y lo excavó como si de tal se tratase, abriendo una zanja de unos $4 \mathrm{~m}$. de ancha por unos $17 \mathrm{~m}$. de larga en la parte alta de la ladera $\mathrm{N}$ y con una dirección $\mathrm{E}-\mathrm{W}$, intentando llegar al centro del «túmulo» y seccionando la estructura que lo formaba (fig. 3:2).

J. Zuazo había realizado con anterioridad una serie de catas en la parte alta, donde halló (ZUAZO PALACIOS, J. 1916, 59) varias tumbas, con huesos, cenizas, molinos y trituradores.

J. Sánchez Jiménez suponía para el centro del «túmulo» la presencia de una cueva como cámara

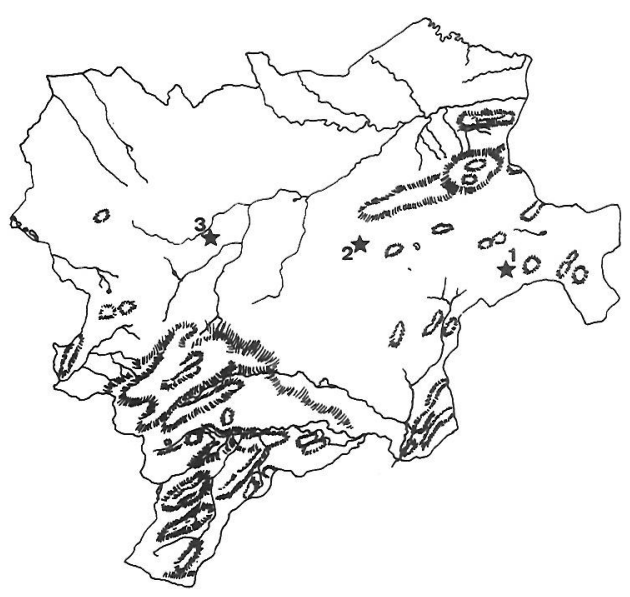

Figura 1.2.-Provincia de Albacete. Situación de los yacimientos. 1: Cerrico Redondo. 2: Las Peñuelas. 3: Mina de Don Ricardo.

central, tal y como en 1929 hacía encontrado en la excavación de Las Peñuelas, donde pensaba que se encontraba el enterramiento central, considerando como tumbas secundarias los hallazos de J. Zuazo Palacios.

En la zanja señala una «hoguera» de unos 10 $\mathrm{cm}$. de espesor, se asienta sobre una plataforma de unos $10-20 \mathrm{~cm}$. de espesor «formada por un mortero calizo». En la capa cenicienta encontró los materiales, que interpretó como ajuares funerarios de tumbas de incineración, ya que jamás encontró cadáver o hueso humano. Los materiales arqueológicos-cerámicas, maderos, semillas, molinos, etc- se concentraban en doce puntos. Menciona la presencia de vasijas «unas dentro de otras» con semillas, rodeadas de pesas de arcilla y bolas del mismo material.

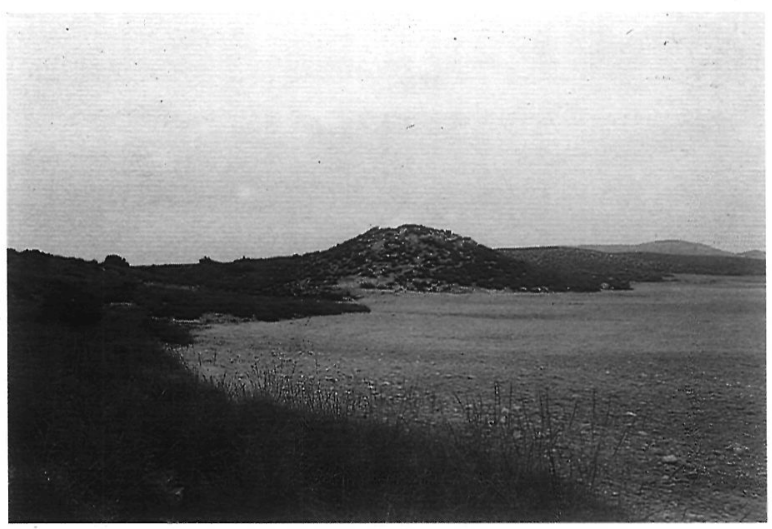

Figura 2.-Cerrido Redondo (Montealegre del Castillo). 


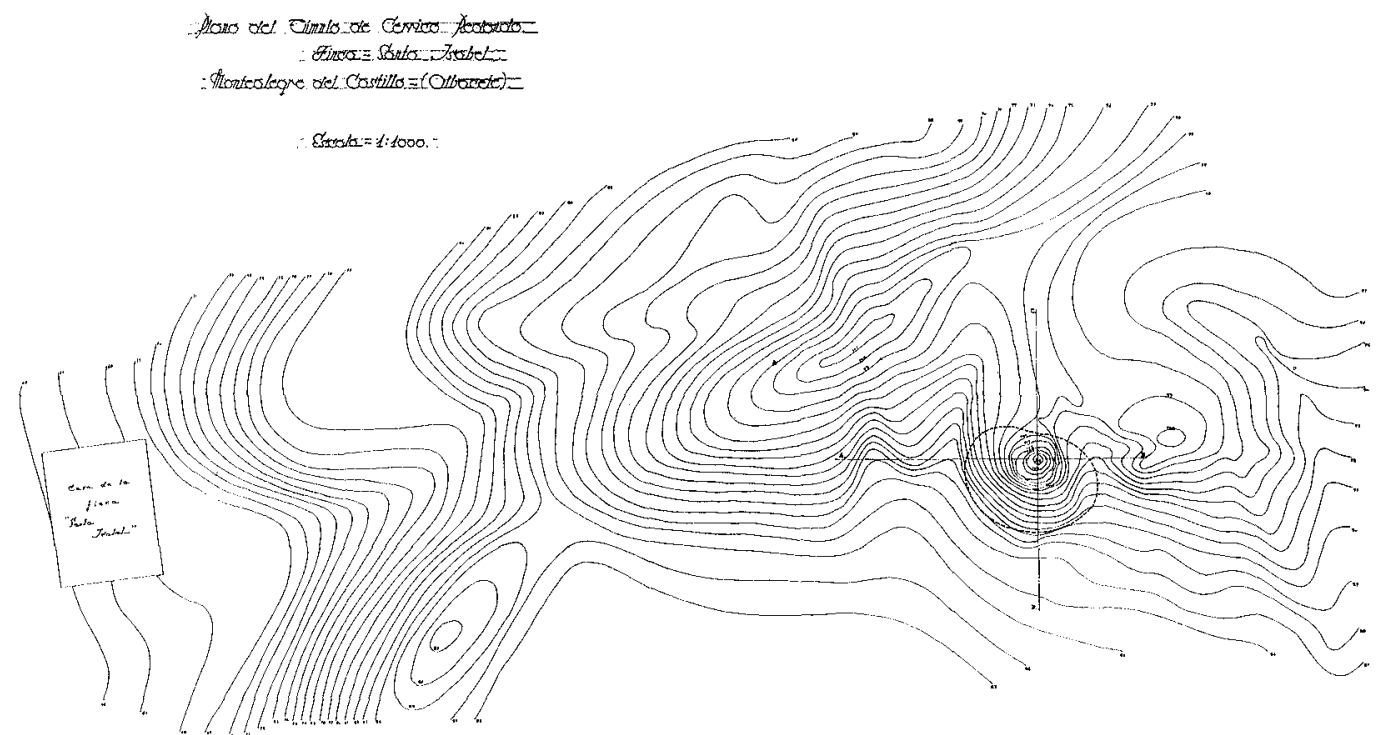

Soxtign. C.D.

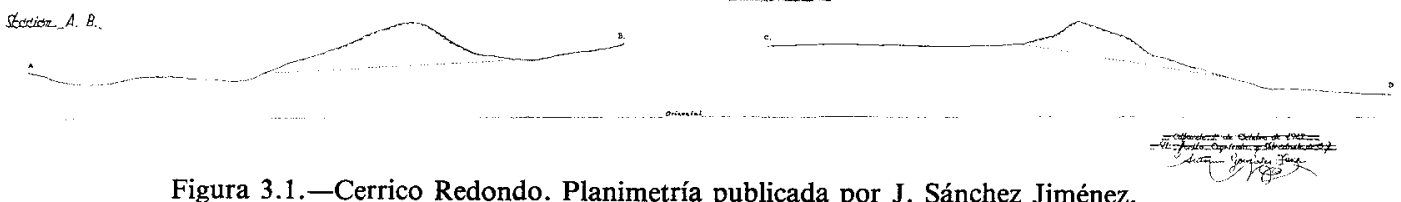

Figura 3.1.-Cerrico Redondo. Planimetría publicada por J. Sánchez Jiménez.

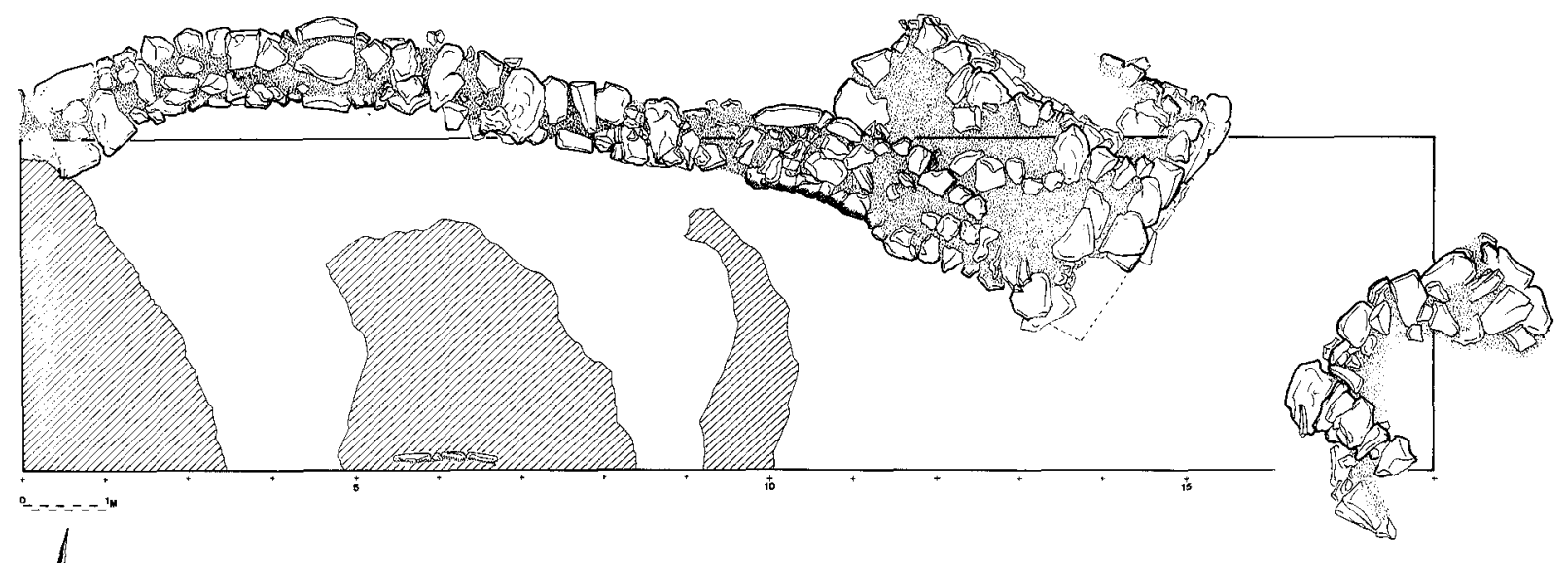

Roca natural

Señales de incendio

barro

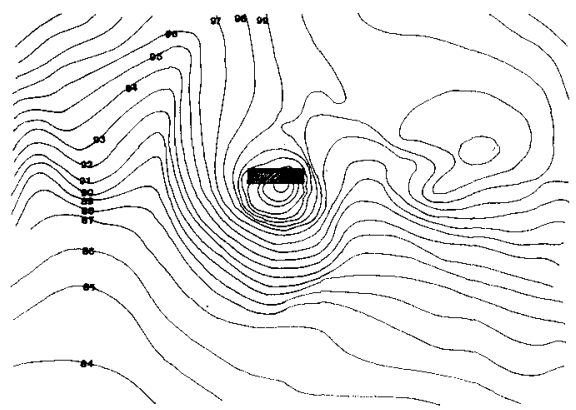

Figura 3.2.-Cerrico Redondo. Planimetría de la zona excavada por J. Sánchez Jiménez, realizada por J. L. Simón. 
Señala la presencia de muros y los interpreta como la estructura exterior del túmulo.

\section{I.3. Inventario de materiales:}

Exceptuando el crisol que recogimos en una de nuestras prospecciones en la escombrera de la excavación, el resto de los materiales se encontraban en el Museo Provincial de Albacete.

J. Zuazo Palacios señaló un molino, un triturador, una «jarra» con asas y seis cuencos, hoy en paradero desconocido.

\section{Cerámica:}

Vaso de borde recto, labio curvo, cuerpo semiesférico, base convexa. Superficie exterior: alisada. Superficie interior: alisada. Pasta: buena calidad (fig. 4:1). N. ${ }^{\circ}$ de inventario: 3585.

Vaso de borde recto, labio curvo, cuerpo semiesférico, base convexa. Superficie exterior: espatulada. Superficie interior: espatulada. Pasta: buena calidad (fig. 4:2). N. ${ }^{\circ}$ de inventario: 3569.

Vaso de borde recto, labio curvo, cuerpo semiesférico, base convexa. Superficie exterior: alisada. Superficie interior: alisada. Pasta: buena calidad (fig. 4:3). N. ${ }^{\circ}$ de inventario: 4022.

Vaso de borde recto, labio apuntado, cuerpo semiesférico, base convexa. Superficie exterior: bruñido-alisada. Superficie interior: alisada. Pasta: buena calidad (fig. 4:4). N. ${ }^{\circ}$ de inventario: 3572 .

Vaso de borde entrante, labio curvo, cuerpo esférico, base convexa. Superficie exterior: bruñidoalisada. Superficie interior: alisada. Pasta: buena calidad (fig. 4:5). N. ${ }^{\circ}$ de inventario: 3565.

Vaso de borde recto, labio curvo, cuerpo semiesférico, base plana. Superficie exterior: alisada. Superficie interior: alisada. Superficie interior: alisada. Pasta: buena calidad (fig. 4:6). N. ${ }^{\circ}$ de inventario: 3564 .

Vaso de borde recto, labio apuntado, cuerpo semiesférico, base convexa. Superficie exterior: bruñido-alisada. Superficie interior: alisada. Pasta: buena calidad (fig. 4:7). N. ${ }^{\circ}$ de inventario: 3563 .

Vaso de forma compuesta. Borde exvasado labio curvo, cuello troncocónico, cuerpo inferior semiesférico, carena media, asas tipo mamelón alargado en vertical, dos, y perforados en la misma dirección. Superficie exterior: bruñido-alisada. Superficie interior:espatulada. Pasta: buena calidad.
Boca ovalada (fig. 4:8). N. ${ }^{\circ}$ de inventario: 3594.

Vaso de forma compuesta. Borde exvasado, labio curvo, cuello troncocónico, cuerpo inferior semiesférico, carena media, asa tipo cinta de implantación vertical y sección ovalada. Superficie exterior: bruñido alisada. Superficie interior: alisada. Pasta: buena calidad. Boca ovalada y cuerpo asimétrico (fig. 4:9). N. ${ }^{\circ}$ de inventario: 3584.

Vaso de borde exvasado, labio curvo, cuello hiperbólico, cuerpo elipsoide horizontal, base convexa. Superficie espatulada: alisada. Superficie interior: espatulada. Pasta: buena calidad (fig. 5:1). N. ${ }^{\circ}$ de inventario: 3587.

Vaso de borde exvasado, labio curvo, cuello hiperbólico, cuerpo elipsoide horizontal, base convexa, asa de cinta de implantación vertical de sección ovalada y arranque del labio del vaso. Superficie exterior: alisada. Superficie interior: alisada. Pasta: buena calidad (fig. 5:2). N. ${ }^{\circ}$ de inventario: 3562 .

Vaso de borde exvasado, labio curvo, cuello hiperbólico, cuerpo elipsoide horizontal, base convexa, asa de cinta de implantación vertical de sección ovalada. Superficie exterior: alisada. Superficie interior: alisada. Pasta: buena calidad (fig. 5:3). N. ${ }^{\circ}$ de inventario: 3595 .

Vaso de borde exvasado, labio curvo, cuello hiperbólico, cuerpo elipsoide horizontal, base convexa. Superficie exterior: alisada. Superficie interior: alisada. Pasta: buena calidad (fig. 5:4). N. ${ }^{\circ}$ de inventario: 3586.

Vaso de borde exvasado, labio curvo, cuello hiperbólico, cuerpo elipsoide horizontal, base convexa. Superficie exterior: alisada. Superficie interior: alisada. Pasta: buena calidad (fig. 5:5). N. ${ }^{\circ}$ de inventario; 5588.

Vaso de borde exvasado, labio curvo, cuello troncocónico, cuerpo elipsoide horizontal, base convexa, dos asas del tipo mamelón en los extremos de un eje. Superficie exterior: alisada. Superficie interior: alisada. Pasta: buena calidad (fig. 5:6). N. ${ }^{\circ}$ de inventario: 3593.

Vaso de borde recto, labio curvo, cuerpo elipsoide vertical, superficie exterior espatulada. Superficie exterior: espatulada. Superficie interior: espatulada. Pasta: buena calidad. Sin inventariar.

Vaso de borde recto, labio curvo, cuerpo semielipsoide vertical, base convexa, asas del tipo mamelón. Superficie exterior: espatulada. Superficie interior: espatulada. Pasta: buena calidad (fig. 6:1). N. ${ }^{\circ}$ de inventario: 3570 . 

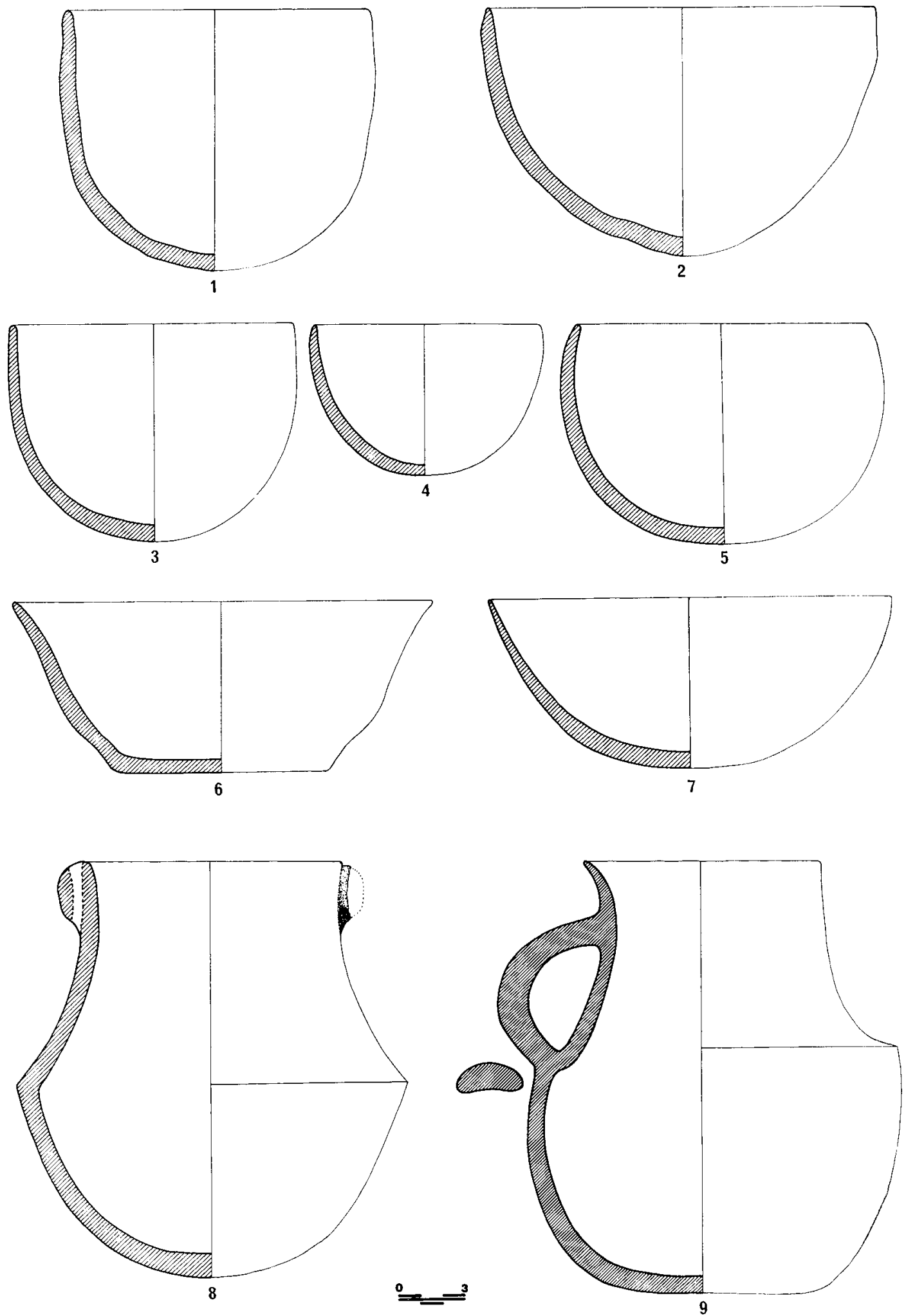

Figura 4.-Cerrico Redondo. Cerámica. 

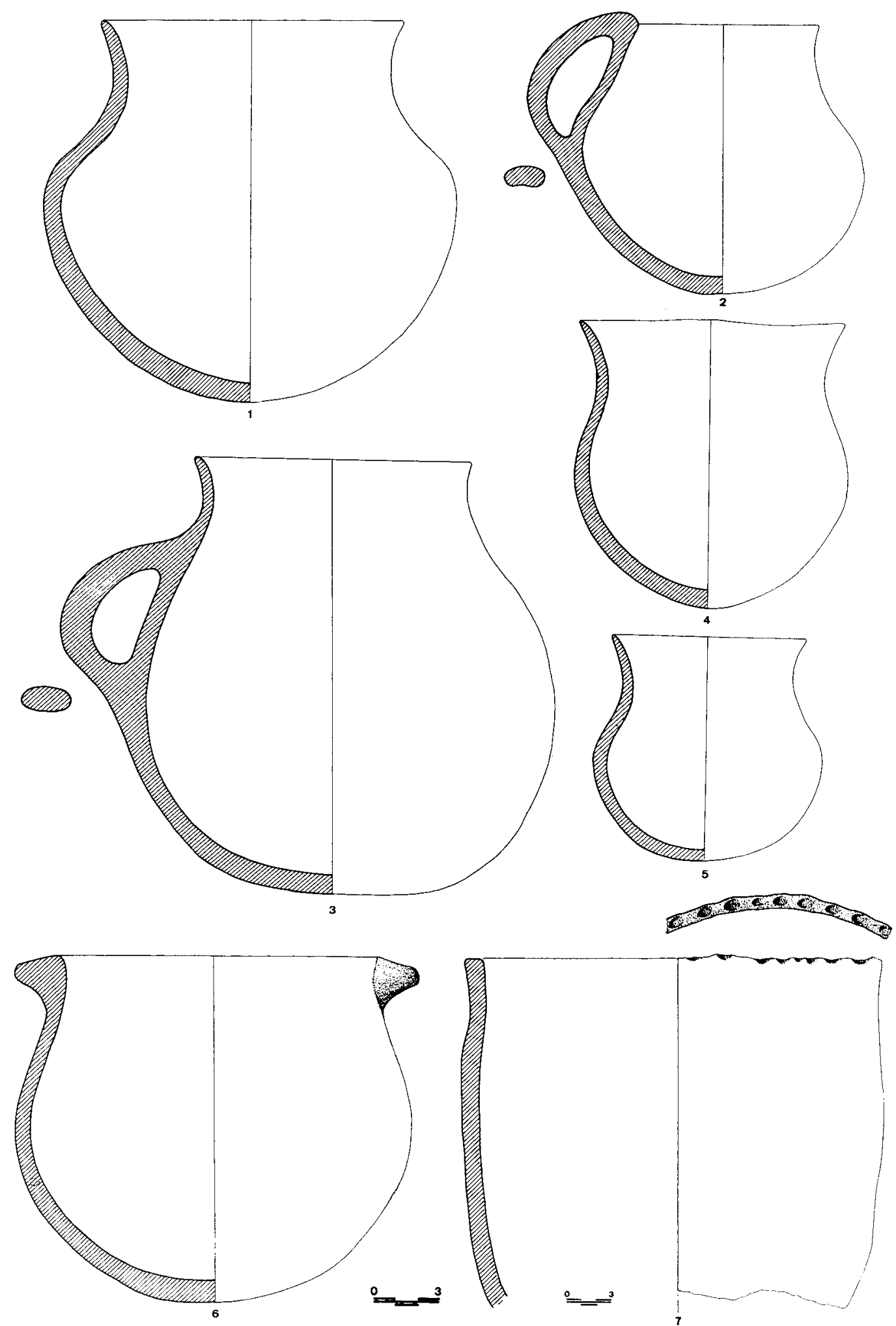

Figura 5.-Cerrico Redondo. Cerámica. 

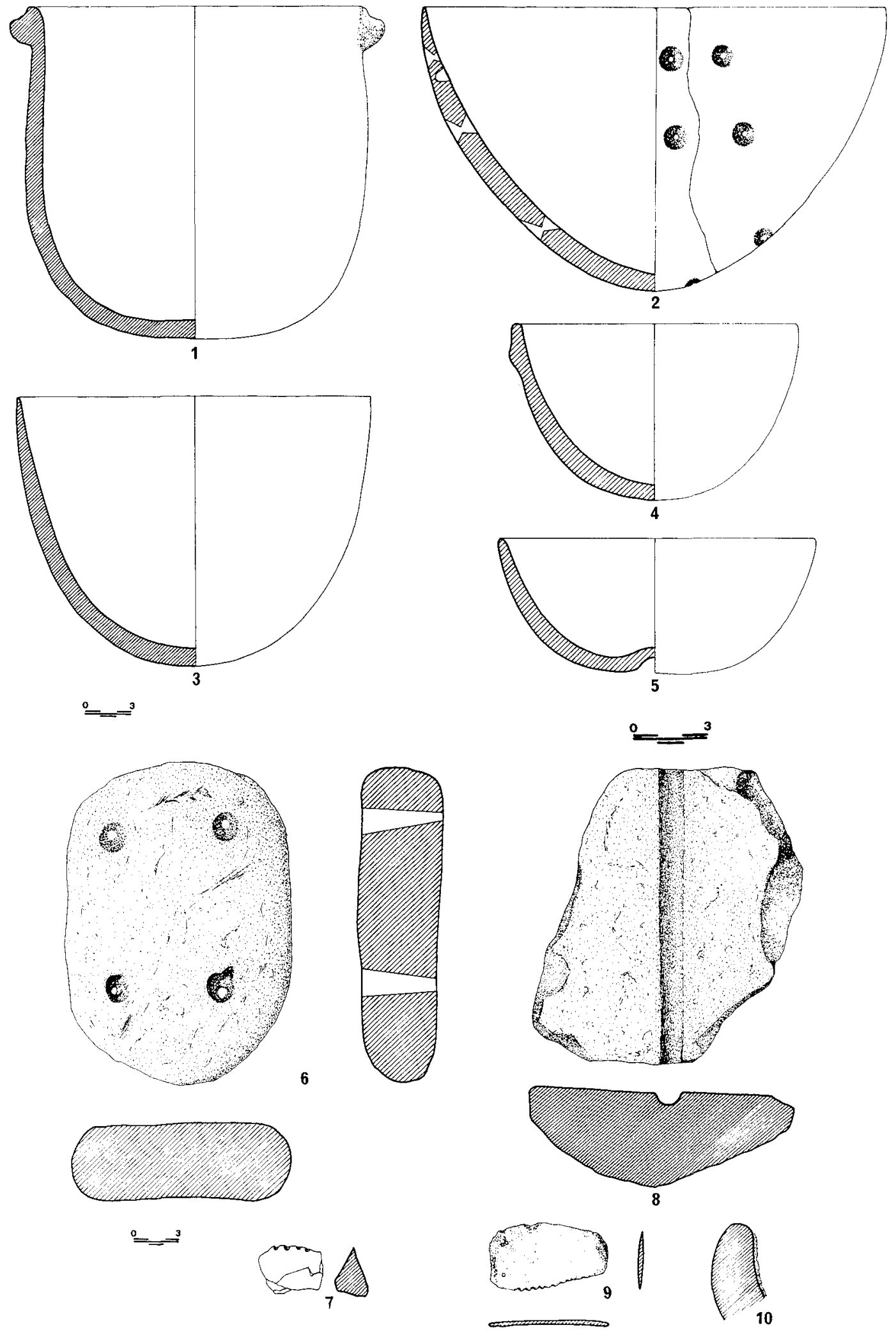

Figura 6.-Cerrico Redondo. 1-5: cerámica. 6: pesa del telar. 7: diente de hoz. 8: molde de fundición. 9: sierra de metal. 10: crisol. 
Vaso de borde recto, labio apuntado, cuerpo semielipsoide vertical, base convexa. Superficie exterior: alisada. Superficie interior: alisada. Pasta: buena calidad, tres pares de perforaciones bicónicas para lañado y una sin terminar, todas a ambos bordes de una rotura (fig. $6: 2$ ). $\mathrm{N}^{\circ}$ de inventario: 3592.

Vaso de borde recto, labio apuntado, cuerpo semielipsoide vertical, base convexa. Superficie exterior: alisada. Superficie interior: alisada. Pasta: buena calidad (fig. 6:3). N. ${ }^{\circ}$ de inventario: 3589 .

Vaso de borde recto, labio curvo, cuerpo semielipsoide vertical, base convexa. Superficie exterior: alisada. Superficie interior: alisada. Pasta: buena calidad (fig. 6:4). N. ${ }^{\circ}$ de inventario: 3590 .

Vaso de borde recto, labio apuntado, cuerpo semielipsoide vertical, base convexa. Superficie exterior: alisada. Superficie interior: alisada. Pasta: buena calidad (fig. 6:5). N. ${ }^{\circ}$ de inventario: 3571 .

Sin inventariar se encuentran:

Un vaso de borde recto, labio plano, cuerpo elipsoide vertical. Superficie exterior: espatulada. Superficie interior: espatulada. Pasta: mediocre calidad. Decoración en el labio por medio de digitaciones (fig. 5:7).

Tambien se han inventariado 23 bordes exvasados de labio curvo y superficies mayoritariamente alisadas, con pastas de buena calidad; un borde exvasado de labio curvo de superficies y pasta grosera. Una asa de cinta de sección ovalada; un borde exvasado de labio curvo y decorado con digitaciones. Nueve fragmentos de carena medias de vasos con superficies alisadas, pastas de buena calidad. Dos fragmentos de carenas de similares características, una con mamelones en la misma y otra con una asa cinta de implantación vertical. Tres bordes exvasados de labio curvo, cuellos troncocónicos o hiperbólicos con cuerpo compuesto que forma una carena media en el vaso.

\section{Lítico:}

Diente de hoz de sección triangular, retoque monofacial continuo (fig. 6:7).

Molinos.

Manos de molino.

\section{Metal:}

Un molde de fundición de varilla, realizado en arenisca con una cara plana en la cual se encuentra un surco central, de sección semicircular, de 0'9 cm. de ancho (fig. 6:8). Número de inventario: 3580 .
Una sierra de cobre o bronce con dos perforaciones de pequeño tamaño en un extremo y un eje dentado. Dimensiones: $4,7 \mathrm{~cm}$. de largo y $2,6 \mathrm{~cm}$. de ancho. Grosor: 0,2 cm. Peso: 6,9 gr. (fig. 6:9). Número de inventario: 3583.

Dos fragmentos de escorias, el primero es de forma esférica y el segundo parece tratarse de varias laminitas en proceso de fundición. Su peso total es de 67,2 gr. Número de inventario: 3581 y 3582 .

Un crisol de cerámica de borde entrante, labio curvo. Superficie exterior: alisada. Superficie interior: alisada cubierta con metal. Pasta: buena calidad (fig. 6:10).

\section{Otros:}

Semillas de trigo

Semillas de, al parecer, una leguminosa

Madera

Esparto carbonizado

Una pesa de telar de forma rectangular con cuatro perforaciones regulares y un lado completamente plano (fig. 6:6).

Una pesa de telar fracturada, la cual conserva dos perforaciones

Fragmento de una pesa de telar.

\section{I.4. Interpretación de los datos de la excavación}

J. Sánchez Jiménez interpretó todos los datos de la excavación bajo un único prisma. Se trataría de un túmulo artificial con cámara central, posiblemente natural aprovechando una cueva tal y como había constatado en Las Peñuelas, de una cista o de una cámara dolménica. En ella se ubicaría el enterramiento de un personaje relevante, rodeado de tumbas secundarias. Las estructuras eran interpretadas como los círculos pertenecientes a la bóveda de la cámara central, formada por anillos concéntricos.

La excavación se centró en la parte superior, cuyas cenizas se consideraban restos de incineraciones secundarias, el «lecho de diez a veinte centímetros de espesor, formado por un mortero calizoarenisco» como el coronamiento del túmulo, del cual «las cenizas se alejaban muy poco». La agrupación en conjuntos de las cerámicas la interpretó como ajuares de diferentes tumbas. No justifica la presencia de los molinos y manos de morteros. 
Desde el conocimiento actual que se posee sobre la Edad del Bronce en la zona oriental de la provincia de Albacete podemos reinterpretar los datos aportados por el yacimiento, que incluimos en el Tipo I de poblados en cerro de la vecina zona de Almansa (SIMÓN 1987). J. Sánchez Jiménez debió excavar parte de una habitación, de la que hoy se conserva (fig. 3:2) un largo muro de 0,90 cm. de grosor y de $0,30 \mathrm{a} 1,50 \mathrm{~cm}$. de altura que en un extremo forma ángulo recto junto al perfil, por lo que no podemos precisar si se trata de una puerta reforzada por doble muro. Frente a este existen restos de un muro de tendencia curva.

El «lecho calizo-arenisco» debe interpretarse como el piso de la habitación, sobre el cual se encontraba una capa cenicienta, procedente del incendio de la techumbre o del hogar de la habitación. Las paredes poseían un zócalo de piedra, el cual se puede hoy en día observar «in situ», y el resto de barro con ramajes, parte del cual fue recogido en el momento de la excavación. En la habitación encontraron troncos, bien de postes o de la techumbre, y un gran conjunto de cerámicas que a juzgar por su situación, disposición y contenido debieron de ser abandonadas de forma brusca, al encontrarse la mayoría de los vasos enteros, algunos llenos de semillas y otros dispuestos cerca de hogares ya que se rodeaban de piedras, barro y «entre carbones». El esparto podría interpretarse como restos de yacijas o de esteras.

En superficie se señala el hallazgo de la sierra de metal y de dientes de hoz, mientras las escorias se encontraron en los niveles de habitación. No se hace mención a la ubicación del molde de fundición.

En la escombrera de la tierra extraída de la habitación localizamos el fragmento de crisol.

En resumen, podemos considerar este yacimiento como típico del Corredor de Almansa, con una gran habitación o cabaña en la parte superior, a la cual se accede por una puerta de gran anchura orientada al $\mathbf{N}$.

\section{I.5. Bibliografía específica del yacimiento:}

ZUAZO PALACIOS, J. 1915: Montealegre del Castillo y su Cerro de los Santos. Madrid.

ZUAZO PALACIOS, J. 1916: Meca. Contribución al estudio de las ciudades ibéricas. Madrid.

SÁNCHEZ JIMÉNEZ, J. 1948: «La cultura del Argar en la provincia de Albacete» III C.A.S.E. Murcia 1947. Cartagena, 73-79.
SÁNCHEZ JIMÉNEZ, J. 1948: «La cultura algárica en Albacete. Notas para su estudio» $A$. $y$ M. S.E.A.E. y P. t. XXIII, c.1-3. Madrid. 96-110.

SÁNCHEZ JIMÉNEZ, J. 1947: Excavaciones y trabajos arqueológicos en la provincia de Albacete de 1942 a 1946. Informes y Memorias N. ${ }^{\circ} 15$. 47-52. Madrid.

\section{LAS PEÑUELAS (POZO CAÑADA-CHINCHILLA)}

\section{II.1. Situacióm:}

El yacimiento se encuentra situado al E de la carretera N-301 de Madrid a Cartagena, a la altura del km. 265'5, de la que dista unos $1230 \mathrm{~m}$. Altura sobre el nivel del mar: $805-790 \mathrm{~m}$. Coordenadas: $38^{\circ}$ 50 ' 24'" de lat. $\mathrm{N}$ y $1^{\circ} 44^{\prime} 50^{\prime \prime}$ de long. W del meridiano de Greenwich (fig. 1:2.2).

\section{II.2. La excavación:}

En 1928 llegó a la Comisión de Monumentos de Albacete la denuncia de la expoliación por parte de unos vecinos de Pozo Cañada de una morra, en busca de un «tesoro».

J. Sánchez Jiménez, acompañado de otras autoridades, se personó en el lugar, requisó los materiales que se encontraban en manos de los expoliadores e inspeccionó la morra, dictaminando que se trataba de un túmulo sobre una cueva (fig. 7).

Denominó al yacimiento como «La Peñuela I», describiéndolo como un túmulo, el cual poseía en su parte central una bóveda por aproximación de

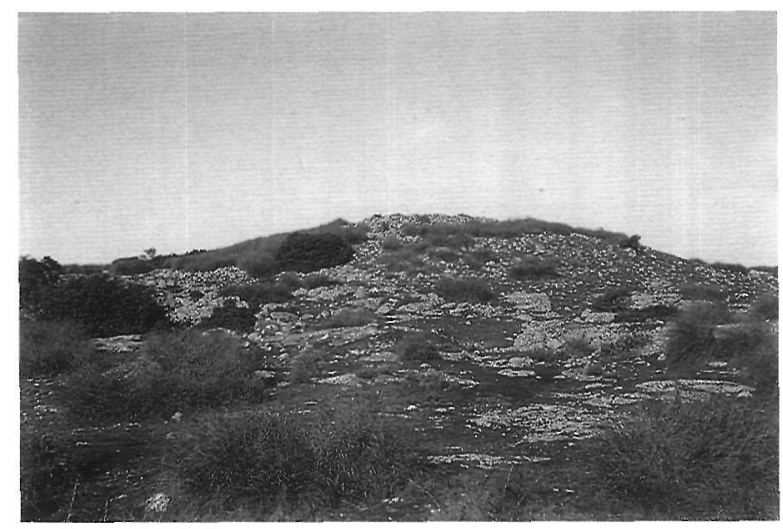

Figura 7.-La Peñuela II. 
hiladas, rota en su parte superior por los expoliadores, y en donde existía una «gran urna de enterramiento» con huesos carbonizados y cenizas. La cueva es de grandes dimensiones, aunque en ocasiones se estrecha y hace difícil su acceso, encontrándose en la parte más profunda los objetos que fueron requisados. Se accede a la cueva por la pared NW de la bóveda, a través de una puerta adintelada con una gran laja de $1 \mathrm{~m}$. de altura que da acceso a una cámara artificial de planta ovalada de pequeñas dimensiones y en donde encontró fragmentos de un cuenco «algárico».

En el exterior se aprecian restos de estructuras «rectangulares» que las interpretó como restos de poblado y una gran zanja excavada en la roca y vaciada por los expoliadores como el camino de acceso al poblado.

En la parte alta del cerro de La Peñuela observó otro túmulo intacto con «un ligero hundimiento», junto al cual se apreciaban estructuras «en disposición circular, cuadrada u oblonga» (fig. 8). Solicitó, con D. Silverio de la Torre, el correspondiente permiso y dotación para su excavación, comenzándola en 1929. Se realizaron dos zanjas en $T$ (fig. 12) con unas dimensiones cada una de $5 \mathrm{~m}$. de ancho por unos $10 \mathrm{~m}$. de largo, seccionando el «túmulo» desde su vértice hasta su radio exterior.

Descubrió que el «cono túmular» se había formado «mediante círculos concéntricos y escalonados por grandes piedras» entre los que encontró res-

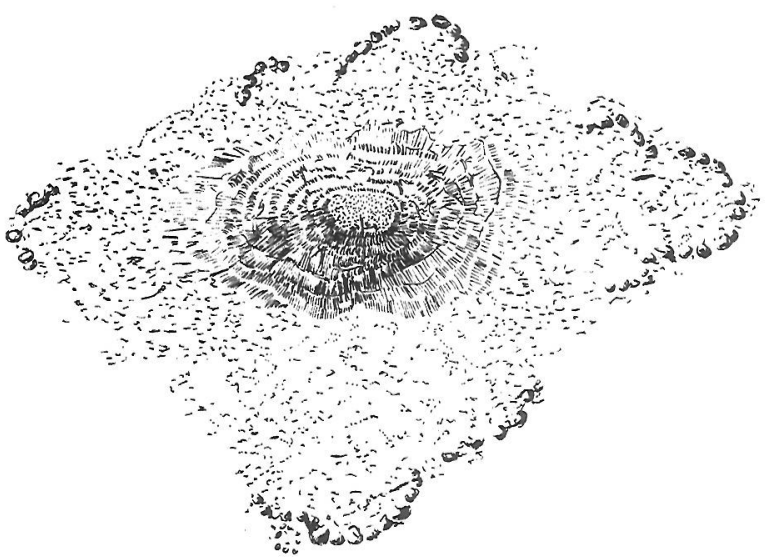

Figura 8.-La Peñuela II. Planimetría publicada por J. Sánchez Jiménez.

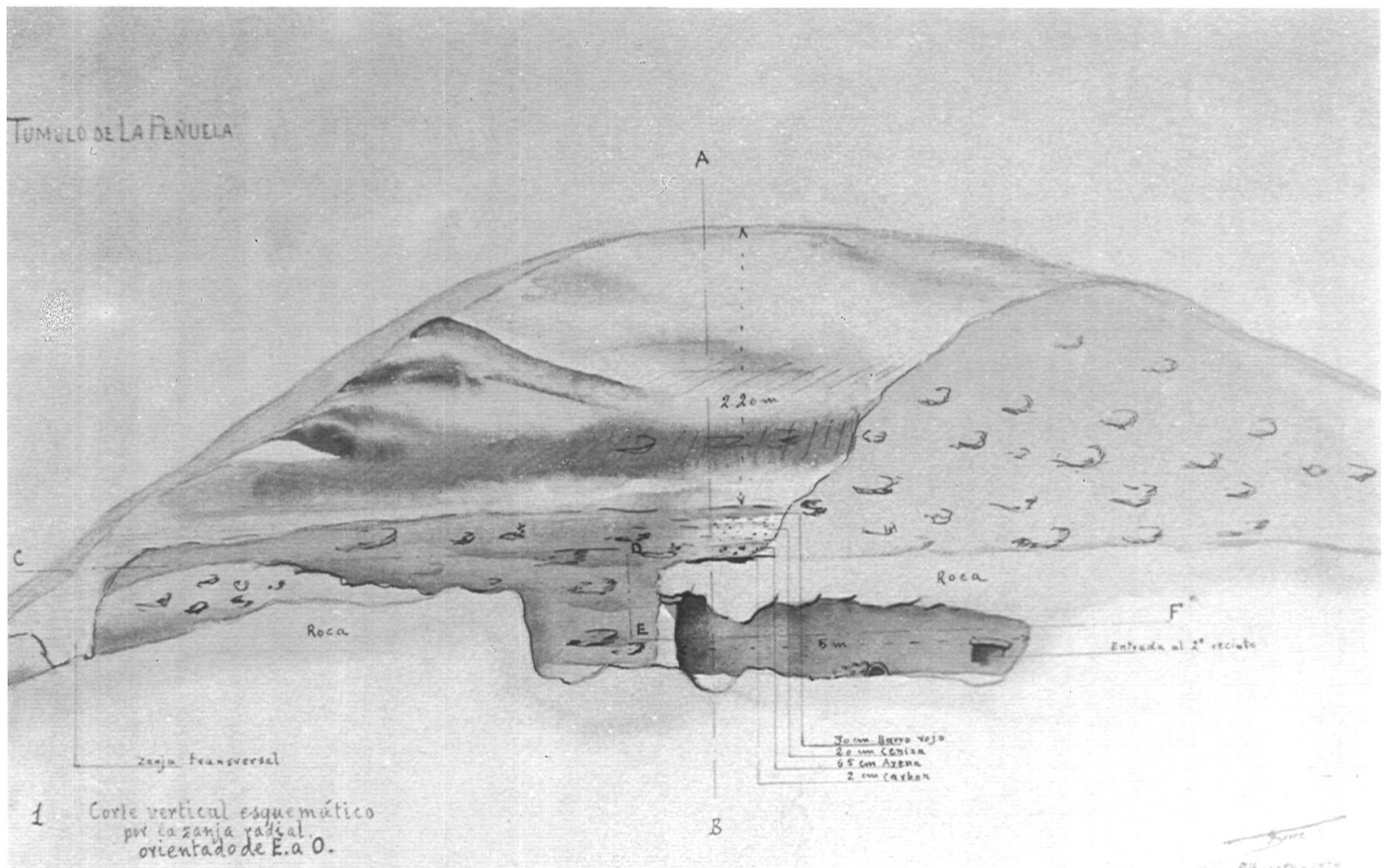

Figura 10.-La Peñuela II. Planimetría de las excavaciones de J. Sánchez Jiménez. 


\section{TUMULO DELARENUELA.}

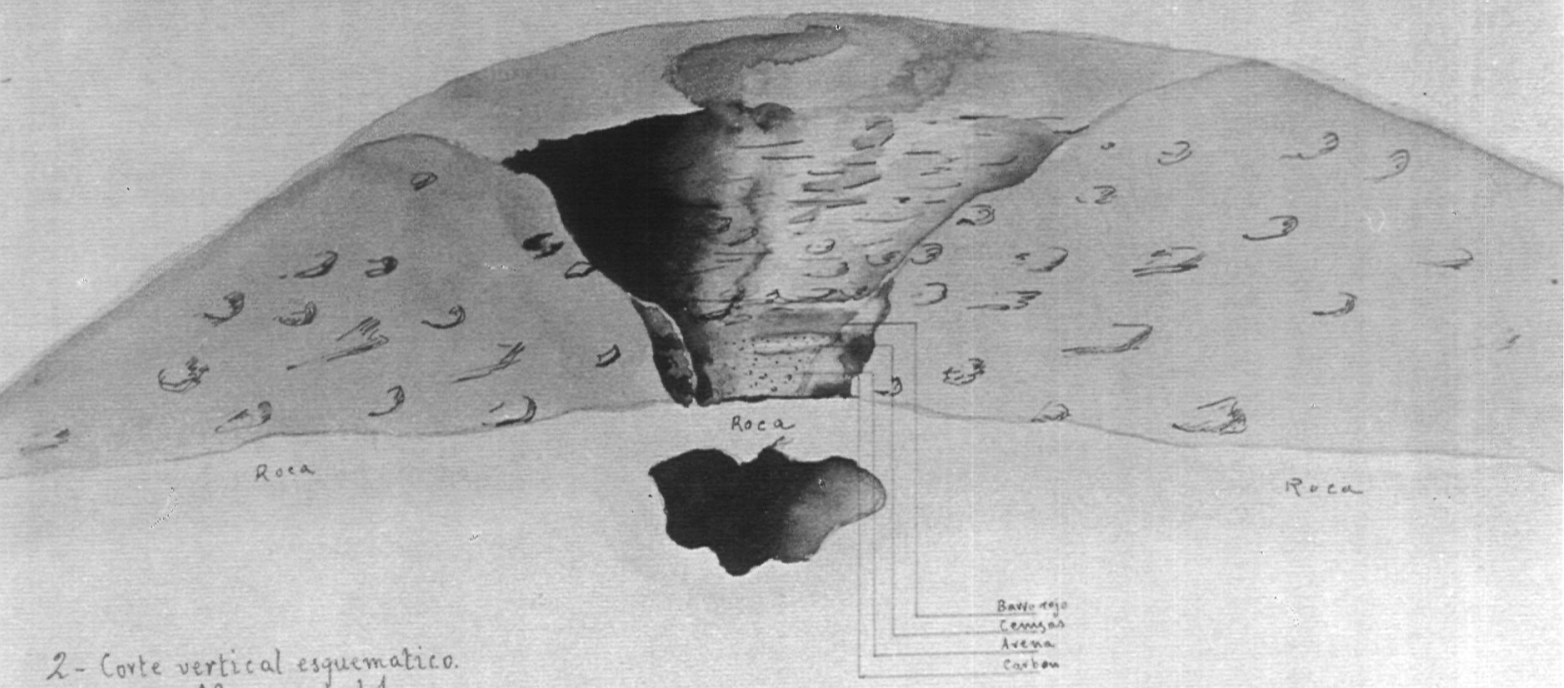

por: $A B$ normal al 1

Figura 11.-La Peñuela II. Planimetría de las excavaciones de J. Sánchez Jiménez.

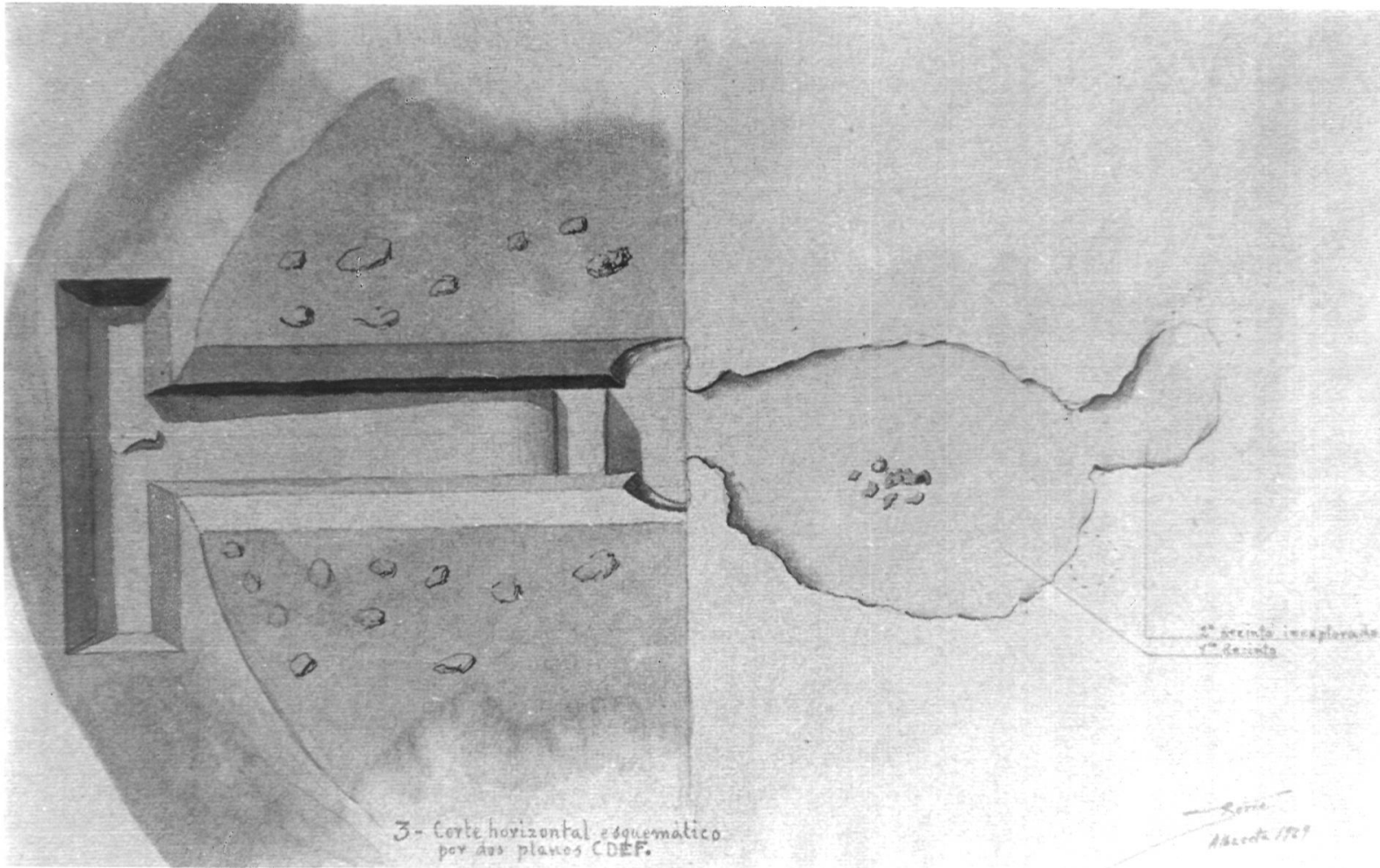

Figura 12.-La Peñuela II. Planimetría de las excavaciones de J. Sánchez Jiménez. 
tos de cerámicas, molinos, núcleos de sílex, etc, que relacionó con las tumbas, al tiempo que se señala la no apreciación del rito funerario ya que no encontraron en ningún momento restos humanos, ni incinerados ni inhumados (fig. 9: $b$ y c).

Se localizó una cueva con entrada adintelada, la cual da acceso a una sala de medianas dimensiones y ésta a otra que quedó sin explorar. Se encontraron dos grandes vasos, restos de fauna y cantos de río.

Se excavó parte de dos estructuras denominadas «fondos de cabañas» las cuales proporcionaron cerámica y niveles con ceniza.

\section{II.3. Inventario de los materiales:}

\section{LA PEÑUELA I}

\section{Cerámica:}

Vaso de borde exvasado, labio curvo, cuerpo compuesto por una parte superior troncocónica curvada y una inferior semiesférica, formando una carena de posición media-baja. Superficie exterior: alisada. Superficie interior: alisada. Pasta y cocción: de buena calidad (fig. 13:1).

Vaso de borde exvasado, labio curvo, cuello hiperbólico, cuerpo elipsoide horizontal asimétrico, asa de cinta de implantación vertical y sección ovalada, base convexa. Superficie exterior: bruñidoalisada. Superficie interior: alisada y erosionada. Pasta y cocción: de buena calidad (fig. 13:2).

Cucharón cerámico, de borde recto y erosionado, labio curvo, cuerpo semielipsoide horizontal, asa de sección cuadrangular fracturada, base convexa. Superficie exterior: alisada. Superficie interior: alisada. Pasta y cocción: de buena calidad (fig. 13:3). N. ${ }^{\circ}$ de inventario: 1195.

\section{Lítico:}

Fragmento de hacha de sección ovalada, filo curvo muy desgastado, superficies muy pulidas. N. ${ }^{\circ}$ de inventario: 225 .

\section{Óseo:}

Punzón realizado en un hueso largo, del cual se conserva la mitad del caña central, parte de la epífisis y el extremo distal trabajado en punta (fig. 13: 7). N. ${ }^{\circ}$ de inventario: 221.
Punta de flecha de pedúnculo y aletas, con profundas señales de pulido, sección del pedúnculo circular y de hoja semiovalada (fig. 13:6). N. ${ }^{\circ}$ de inventario: 222.

\section{Metal:}

Puñal de remaches del tipo III de B. Blance. Posee tres perforaciones dispuestas triangularmente, sin los remaches, dos pequeñas muescas laterales que podrían ser parte del enmangue. Dimensiones: 14,5 $\mathrm{cm}$. de alto, $4,6 \mathrm{~cm}$. de ancho y $0,2 \mathrm{~cm}$. de grosor. Peso: 48,9 gr. (fig. 13:4). N. ${ }^{\circ}$ de inventario: 224 .

Punta de flecha con pedúnculo y aletas. Sección de la hoja triangular y cuadrangular del pedúnculo. Dimensiones: $7,6 \mathrm{~cm}$. de largo, $1,4 \mathrm{~cm}$. de ancho y 0,3 cm. de grosor. Peso: 7 gr. (fig. 13:5). N. ${ }^{\circ}$ de inventario: 223.

\section{LA PEÑUELA II}

\section{Procedente de la cueva:}

\section{Cerámica:}

Vaso de grandes dimensiones de borde exvasado, labio curvo, cuello hiperbólico, cuerpo elipsoide vertical decorado con un cordón horizontal a la altura del cuello del cual parten cuatro filas de mamelones situado en los extremos de dos ejes perpendiculares, dos con cuatro mamelones y dos con cinco, entre los cuales se sitúan también de forma vertical cordones en número de cinco, tres, tres y cuatro ( 4 mamelones, 5 cordones, 5 mamelones, 3 cordones, 4 mamelones, 3 cordones 5 mamelones, 4 cordones), todas las líneas desviadas de derecha a izquierda. Superficie exterior: alisada-espatulada. Superficie interior: alisada-espatulada. Pasta y cocción de buena calidad (fig. 14:1). N. ${ }^{\circ}$ de inventario: 1190 .

Vaso de borde recto, labio plano, cuerpo elipsoide vertical, base convexa, asas del tipo mamelón, agrupadas en dos pares en los extremos de un eje y de forma individual en los extremos del eje perpendicular al primero. Superficie exterior: espatulada. Superficie interior: espatulada. Pasta y cocción de buena calidad (fig. 14:2).

\section{Fauna:}

Restos de cornamenta de ciervo. 


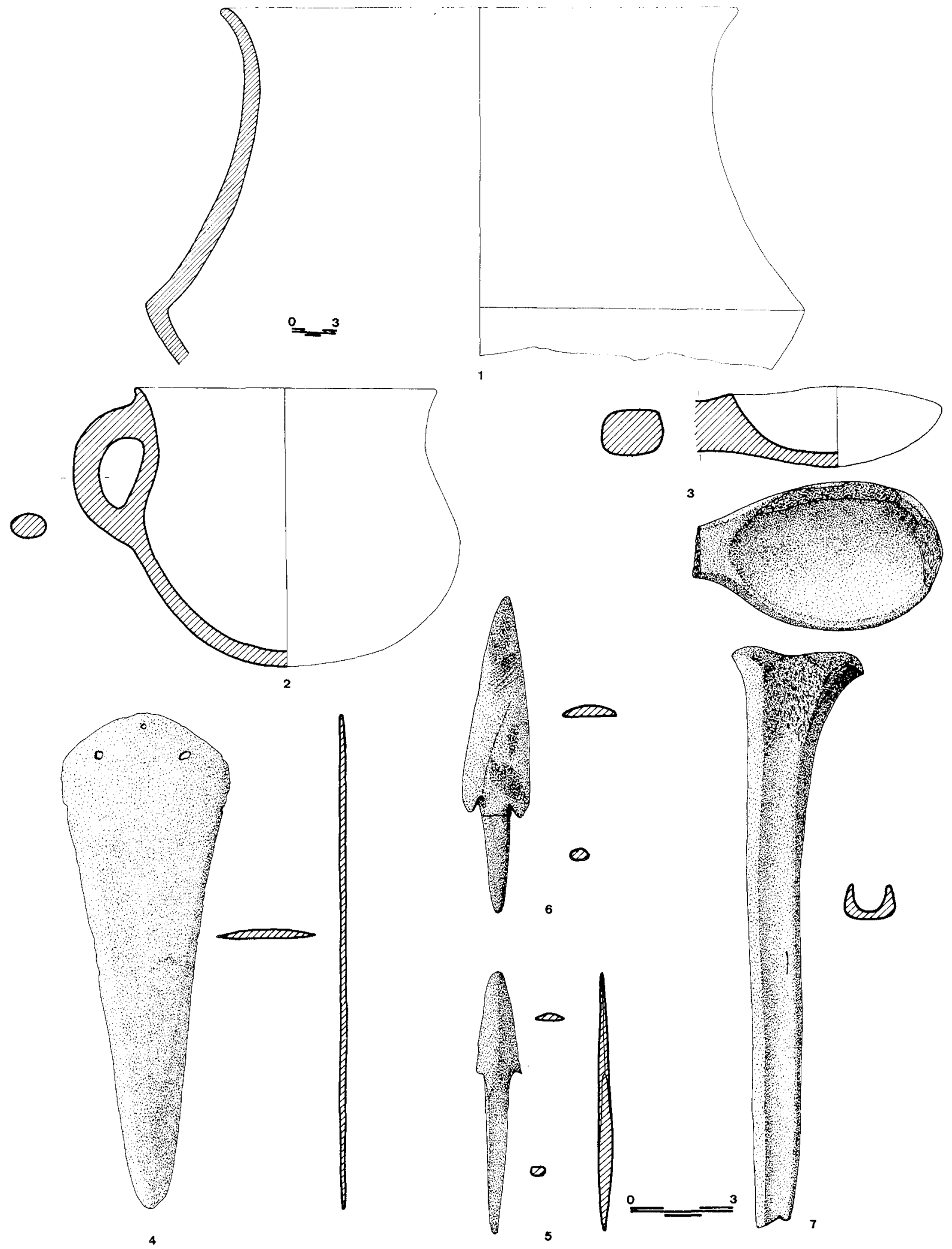

Figura 13.-La Peñuela I.-1:3: cerámica. 4-5: metal. 6-7: hueso. 

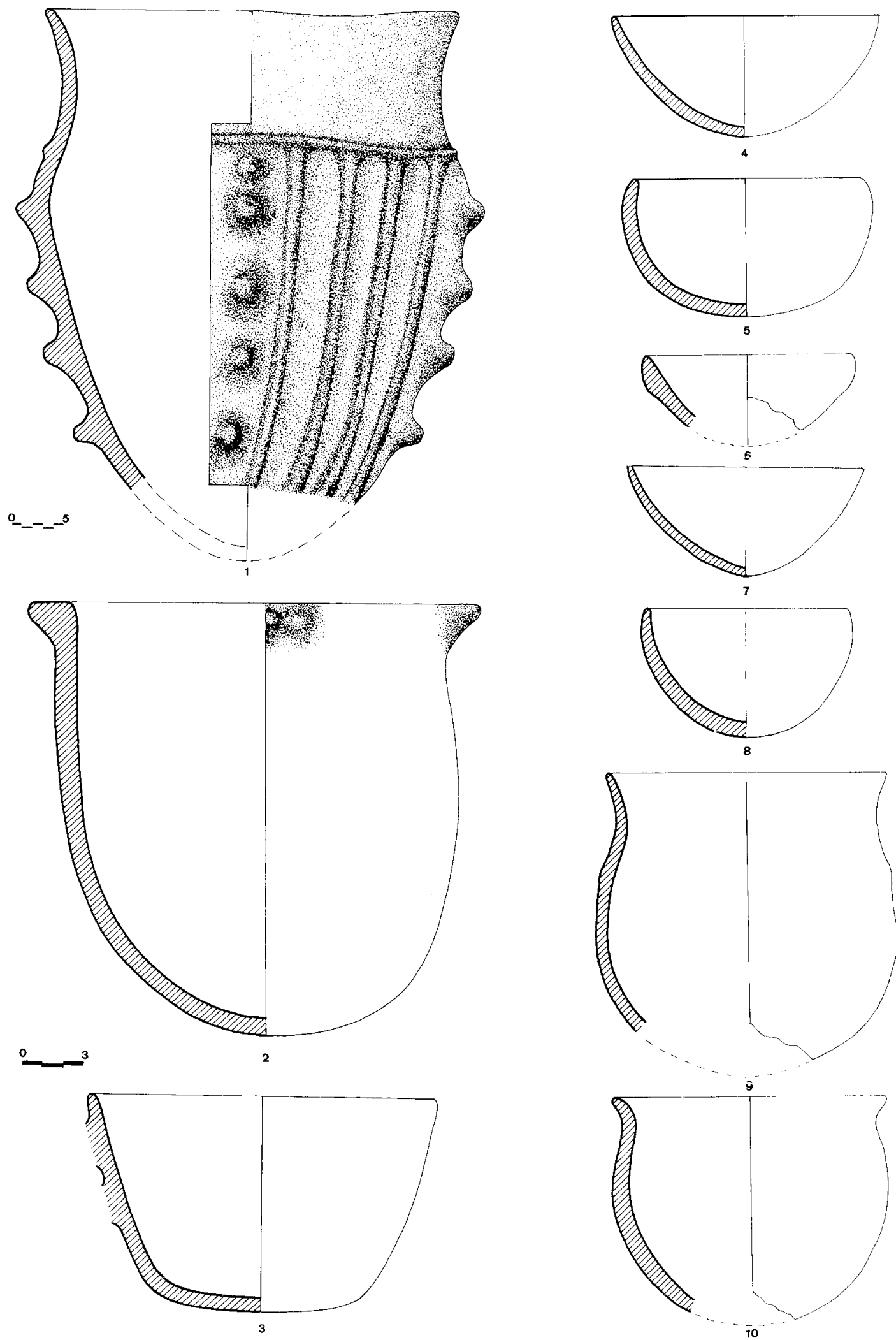

Figura 14.-La Peñuela II. Cerámica. 


\section{Procedentes de la excavación en el exterior:}

\section{Cerámica:}

Vaso de borde recto, labio curvo, cuerpo semiesférico, base apalanda. Superficie exterior: alisada. Superficie interior: alisada. Pasta y cocción: de buena calidad (fig. 14:3).

Vaso de borde recto, labio curvo, cuerpo semiesférico, base convexa. Superficie exterior: alisada. Superficie interior: alisada. Pasta y cocción: de buena calidad (fig. 14:4). N. ${ }^{\circ}$ de inventario: 1193.

Vaso de borde entrante, labio curvo, cuerpo elipsoide horizontal, base convexa. Superficie exterior: espatulada. Superficie interior: espatulada. Pasta y cocción: de buena calidad (fig. 14:5). N. ${ }^{\circ}$ de inventario: 1191.

Vaso de borde recto, labio curvo, cuerpo de casquete esférico, base convexa. Superficie exterior: alisada. Superficie interior: alisada. Pasta y cocción: de buena calidad (fig. 14:6). N. ${ }^{\circ}$ de inventario: 6851 .

Vaso de borde recto erosionado, labio curvo, cuerpo semiesférico, base convexa. Superficie exterior: alisada. Superficie interior: alisada. Pasta y cocción: de buena calidad (fig. 14:7). N. ${ }^{\circ}$ de inventario: 1192.

Vaso de borde recto, labio curvo, cuerpo semiesférico, base convexa. Superficie exterior: alisada. Superficie interior: alisada. Pasta y cocción: de buena calidad (fig. 14:8). N. ${ }^{\circ}$ de inventario: 1194.

Vaso de borde exvasado, labio curvo, cuello hiperbólico, cuerpo esférico, base convexa. Superficie exterior: alisada. Superficie interior: alisada. Pasta y cocción: de buena calidad (fig. 14:9).

Vaso de borde exvasado, labio curvo, cuello hiperbólico, cuerpo esférico, base convexa. Superficie exterior: alisada. Superficie interior: alisada. Pasta y cocción: de buena calidad (fig. 14:10).

Vaso de borde exvasado, labio curvo, cuello hiperbólico, cuerpo esférico, base convexa. Superficie exterior: alisada-espatulada. Superficie interior: alisada-espatulada. Pasta y cocción: de buena calidad (fig. 12:1).

Cuchara o cucharón de cerámica de borde recto, labio curvo, cuerpo semielipsoide, base convexa. Superficie exterior: alisada. Superficie interior: alisada-espatulada. Pasta y cocción: de buena calidad (fig. 12:2). N. ${ }^{\circ}$ de inventario: 2196.

Los fragmentos cerámicos inventariados desde el número 1198 al 1226 pertenecen a bordes generalmente exvasados, de superficies alisadas y espa- tuladas, pastas de buena calidad y en 13 ocasiones con impresiones, generalmente digitaciones, en el labio.

\section{Lítico:}

\section{Sílex:}

Fragmento de un cuchillo con retoque plano en los ejes (fig. 12:4). N. ${ }^{\circ}$ de inventario 1280.

Lasca de sílex tabular. N. ${ }^{\circ}$ de inventario: 1235.

Lascas de sílex. N. ${ }^{\circ}$ de inventario: 1228-1241.

\section{Cuarzo:}

Canto de río con señales de uso por abrasión. N. ${ }^{\circ}$ de inventario: 1256.

Cantos de río y lascas de cuarzo. N. ${ }^{\circ}$ de inventario: $1242-44,1230$ y 1281 .

Ofita:

Lascas. N. ${ }^{\circ}$ de inventario $1233-1239$.

\section{Arenisca:}

Molde de fundición de varilla con surco de sección semicircular (fig. 12:3). N. ${ }^{\circ}$ de inventario: 1259. Caliza:

2 molinos de forma oval.

10 manos de molino y percutores.

Óseo:

Punzón realizado en metatarso o metacarpo II de caballo que conserva entero el canal central, con extremo distal apuntado por medio de abrasión (fig. 12:7). N. ${ }^{\circ}$ de inventario: 1262.

Punzón sobre hueso largo, del que se conserva la mitad del canal central, parte de la epífisis y el extremo distal fracturado (fig. 12:9). N. ${ }^{\circ}$ de inventario: 1263.

Punzón sobre astilla de hueso largo, con resto de la epífisis y el extremo distal apuntado (fig. 12:5). $\mathrm{N} .{ }^{\circ}$ de inventario: 1269.

Punzón sobre astilla de hueso largo, con los extremos apuntados (fig. 12:6). N. ${ }^{\circ}$ de inventario: 1273.

Punzón sobre astilla de hueso largo, con los extremos apuntados (fig. 12:8). N. ${ }^{\circ}$ de inventario: 1275.

Punzón sobre astilla de hueso largo, con un extremo apuntado y otro fragmentado. N. ${ }^{\circ}$ de inventario: 1264 .

Punzón sobre astilla de hueso largo, con un extremo apuntado y el opuesto fracturado. N. ${ }^{\circ}$ de inventario: 1265 . 


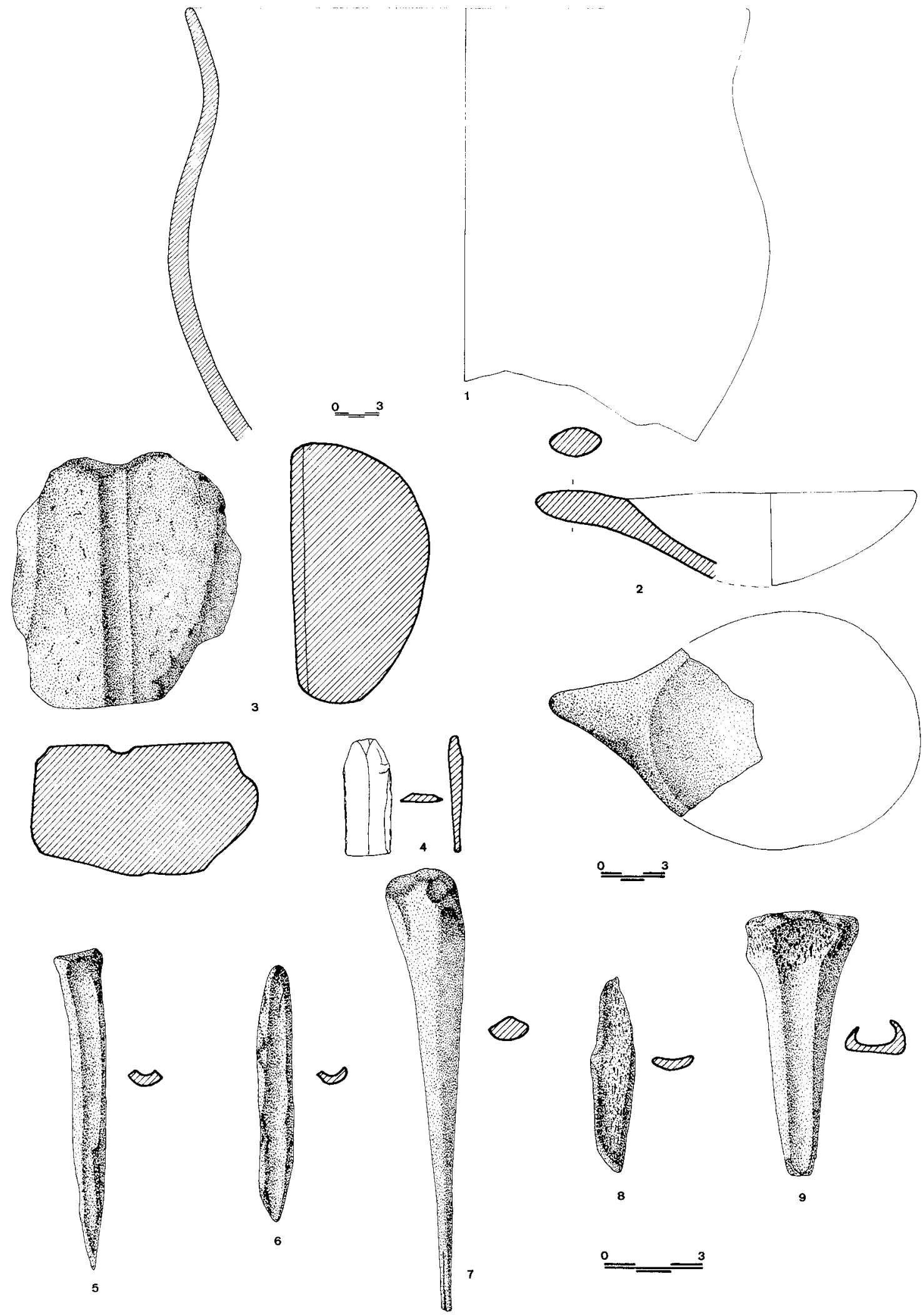

Figura 15.-La Peñuela II. 1-2: cerámica. 3: molde de fundición. 4: lítico. 5-9: hueso. 
Fauna:

Se han inventariado una cuarentena de restos faunísticos pertenecientes a cabra, oveja, caballo, ciervo, gamo, etc.

Otros:

Se han inventariado un fragmento de estera de esparto adherido a una piedra y restos amorfos de esparto, carbones, etc.

Ocre en polvo.

\section{II.4. Interpretación de los datos de la escavación:}

En La Peñuela I J. Sánchez Jiménez no realizó ningún tipo de excavación, limitándose a recoger los materiales y a describir e interpretar las estructuras.

La construcción artificial de la ladera del cerro la consideró como un túmulo funerario con falsa cúpula destruida por los expoliadores. A través de ella se accedería a la cueva natural que cumpliría las funciones de corredor y cámara funeraria.

Las estructuras circundantes las interpretó como los restos del poblado, con camino de acceso y foso defensivo también vaciado por los expoliadores.

En nuestra opinión la estructura artificial de la ladera oriental del cerro se levantó sobre la entrada de una cueva natural. Tenía forma circular, abriéndose en la pared $\mathrm{N}$ una puerta adintelada que da acceso a la cavidad. Alrededor de esta estructura se apuntan otras más o menos concéntricas, tal y como se dan en la Motillas de Ciudad Real, aunque aquí el tamaño es mucho menor.

Rodean a esta construcción otras de diverso tamaño y forma: circular, rectangular, cuadrangular, etc, de las que sólo se conserva un zócalo de piedra de apenas $30 \mathrm{~cm}$. de altura, formado por grandes piedras sin desvastar en los laterales y un relleno de piedras pequeñas. Podría tratarse de paredes con zócalo de piedra y el resto de barro. No obstante no existe este último material en sus alrededores.

$\mathrm{El}$ foso de dirección $\mathrm{E}-\mathrm{W}$ posee unos $2 \mathrm{~m}$. de ancho, unos $4 \mathrm{~m}$. de profundidad y una sección en V. Esta construcción artificial se ensancha en su extremo occidental, donde alcanza los 5 a $6 \mathrm{~m}$. de profundidad. No podemos precisar la función de esta construcción, que quizás deba relacionarse con la recogida y conducción de aguas desde el cerro a las tierras próximas.
En La Peñuela II J. Sánchez Jiménez encontró una estructura formada por muros concéntricos, similares a la de La Peñuela I, en el centro de la cual existe una cueva, por lo que interpretó el yacimiento, al igual que La Peñuela I como un túmulo funerario con una estructura abovedada por medio de aproximación de hiladas. La cueva con entrada artificial adintelada cumpliría las mismas funciones que la anterior, sin embargo nunca se encontraron restos humanos.

Se trata, en nuestra opinión, de una estructura similar en la forma de construcción a la de las Motillas, aunque de menor tamaño. Le rodean unos muros similares a los de La Peñuela I, que en varios casos fueron excavados sin dar fruto alguno, por lo que puede que no sean estructuras de habitación, sino más bien corrales o espacios cerrados accesorios a la estructura central.

\section{II.5. Bibliografía específica del yacimiento:}

SÁNCHEZ JIMÉNEZ, J. 1941: «Urna cineraria del Túmulo II de La Peñuela (Pozo CañadaAlbacete). Actas y Memorias de la S.E.A.E.P. XVI, cuadernos I y II. Madrid; 161-163.

SÁNCHEZ JIMÉNEZ, J. 1947: Excavaciones y trabajos arqueológicos en la provincia de Albacete de 1942 a 1946. Informes y Memorias N. ${ }^{\circ} 15$. Madrid.

SÁNCHEZ JIMÉNEZ, J. 1948: «La cultura del Argar en la provincia de Albacete» III C.A.S.E. Murcia 1947. Cartagena, 73-79.

SÁNCHEZ JIMÉNEZ, J. 1948: «La cultura algárica en Albacete. Notas para su estudio» $A . y$ M. S.E.A.E. y P. t. XXIII, c. 1-3. Madrid, 96-110.

\section{MINA DE D. RICARDO (TIRIEZ-LEZUZA)}

\section{III.1. Situación:}

$\mathrm{El}$ yacimiento se encuentra situado al $\mathrm{S}$ de la carretera local de Balazote a Lezuza por Tiriez, de la que dista unos $1000 \mathrm{~m}$. Altura sobre el nivel del mar: 870 m. s.n.m. Coordenadas: $38^{\circ} 53^{\prime} 19^{\prime \prime}$ de lat. $\mathrm{N}$ y $2^{\circ} 15^{\prime}$ de long. W del meridiano de Greenwich (fig. 1:2.3). 


\section{III.2. La excavación:}

Fue realizada por el propietario de las tierras D. Ricardo García, de modo clandestino. Unos años más tarde visitó el Sr. García Cernuda el yacimiento y convenció al dueño para que entregara los materiales al Museo de Albacete. Se denominó al lugar Mina de D. Ricardo, agradeciendo así la donación, - Dehesa de Caracoles, topónimo de una amplia zona de en Balazote y Tiriez. El topónimo popular con que se conoce el lugar es «la Mina» por la forma y profundidad de la cueva ubicada bajo la estructura artificial cónica alargada de $\mathrm{E}$ a W.

No existen datos de la excavación. Sólo se dispone de los materiales, la observación actual de los restos del yacimiento y de unas escasas notas de J. Sánchez Jiménez (SÁNCHEZ JIMÉNEZ, J. 1947).

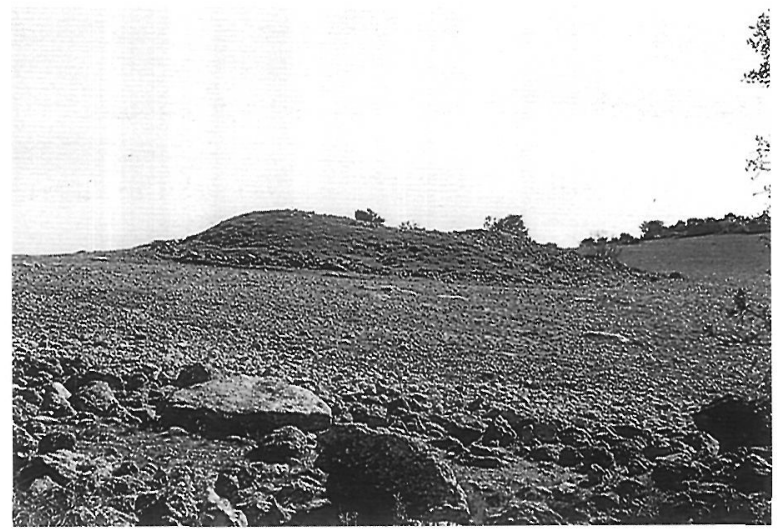

Figura 16.-Mina de Don Ricardo.

\section{III.3. Inventario de los materiales:}

\section{Cerámica:}

Vaso de borde exvasado, labio curvo, cuello hiperbólico, cuerpo esférico, base convexa. Superficie exterior e interior: espatulada. Pasta y cocción: de buena calidad (fig. 17:1).

Vaso de borde exvasado, labio curvo, cuello troncocónico, cuerpo compuesto de parte del cuello y vaso semiesférico, base convexa. Superficies exterior e interior: espatuladas. Pastas y cocción: de buena calidad (fig. 17:2).

Vaso de borde exvasado, labio curvo, cuello hiperbólico, cuerpo compuesto de parte del cuello y vaso semiesférico, situándose la carena a media altura, base convexa. Superficies exterior e interior: bruñido-alisada y erosionada. Pasta y cocción: de buena calidad (fig. 17:3). N. ${ }^{\circ}$ de inventario: 35 .

Vaso de borde recto, labio plano, cuerpo elipsoide vertical, base convexa, dos asas de gran tamaño del tipo mamelón. Superficies exterior e interior: alisada. Pasta y cocción: de buena calidad. Borde decorado con digitaciones (fig. 17:4).

Vaso de borde exvasado, labio curvo, cuello hiperbólico, cuerpo compuesto de parte del cuello y vaso de casquete esférico, formando una carena baja y decorada con 3 mamelones de pequeño tamaño, base convexa. Superficies exterior e interior: bruñido-alisadas. Pasta y cocción: de buena calidad (fig. 18:1). N. ${ }^{\circ}$ de inventario: 40.

Vaso de borde exvasado, labio curvo, cuello troncocónico, cuerpo compuesto de parte del cuello y vaso de casquete esférico formando una carena baja, base convexa. Superficies exterior e interior: bruñido-alisada y erosionada. Pasta y cocción: de buena calidad (fig. 18:2). N. ${ }^{\circ}$ de inventario: 42 .

Vaso de borde exvasado, labio curvo, cuello hiperbólico, cuerpo compuest con la parte superior troncocónica y la inferior semiesférica formando una carena baja decorada con cinco mamelones, base convexa. Superficies exterior e interior: alisadas. Pasta y cocción: de buena calidad (fig. 18:3). N. ${ }^{\circ}$ de inventario: 41.

Vaso de borde exvasado, labio curvo, cuello hiperbólico, cuerpo compuesto de parte del cuello y vaso semiesférico formando una carena media, base convexa. Superficies exterior e interior: bruñido-alisadas. Pasta y cocción: de buena calidad (fig. 18:4). N. ${ }^{\circ}$ de inventario: 36.

Vaso de borde exvasado, labio curvo, cuello hiperbólico con cuatro perforaciones de pequeño tamaño en los extremos de dos ejes perpendiculares, cuerpo esférico, formando una carena alta, base aplanada. Superficies exterior e interior: alisadas. Pasta y cocción: de buena calidad (fig. 18:5). N. ${ }^{\circ}$ de inventario: 37.

Vaso de borde exvasado, labio curvo, cuello cilíndrico, cuerpo compuesto de parte del cuello y vaso semiesférico formando una carena media, base convexa. Superficies exterior e interior: alisadas y erosionadas. Pasta y cocción: de buena calidad (fig. 18:6). N. ${ }^{\circ}$ de inventario: 86.

Vaso de borde entrante, labio curvo, cuerpo esférico. Superficies exterior e interior: espatuladas. Pasta y cocción: de mediocre calidad (fig. 18:7). N. ${ }^{\circ}$ de inventario: 38 . 

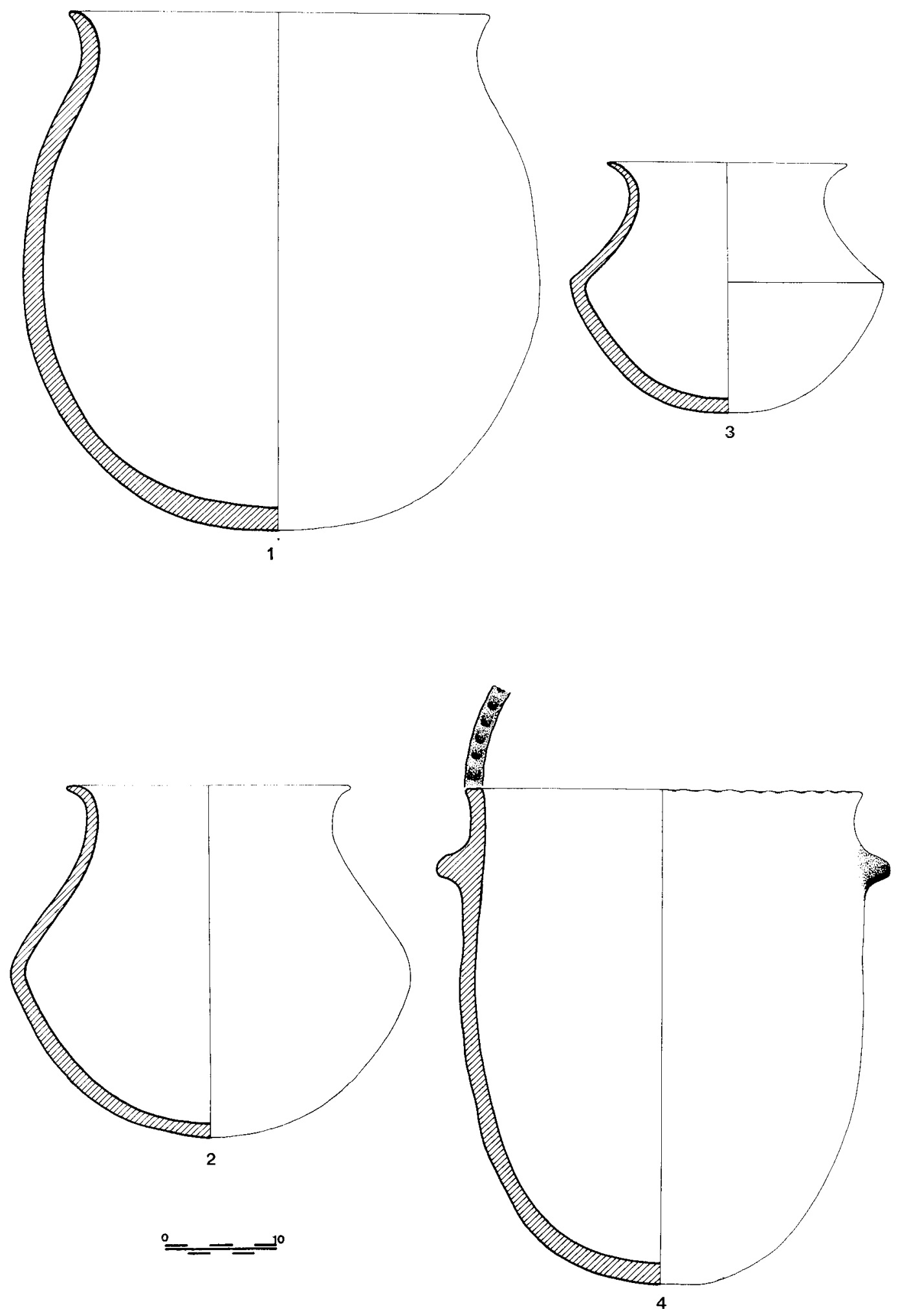

Figura 17.-Mina de Don Ricardo. Cerámica. 

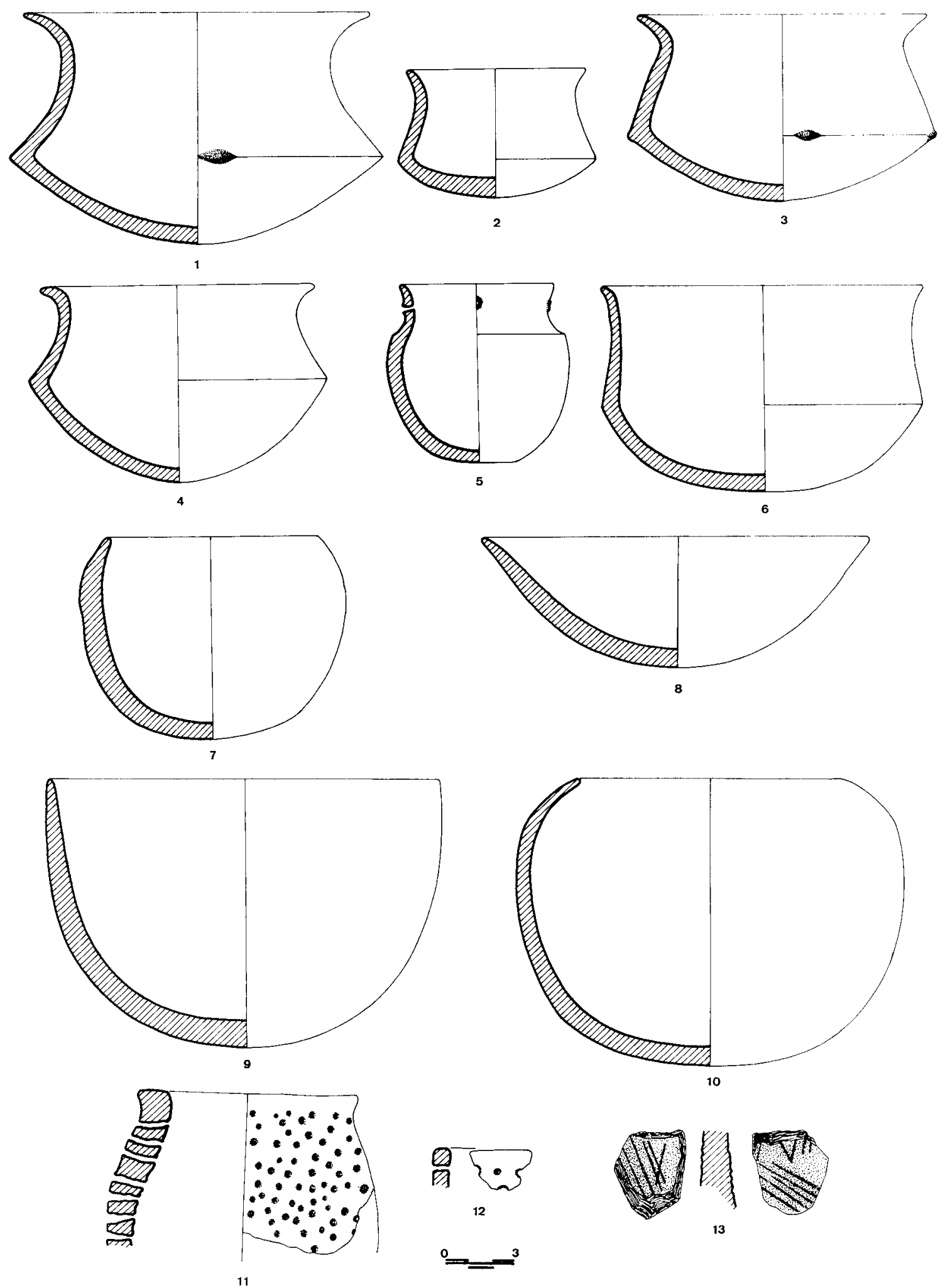

Figura 18.-Mina de Don Ricardo. Cerámica. 


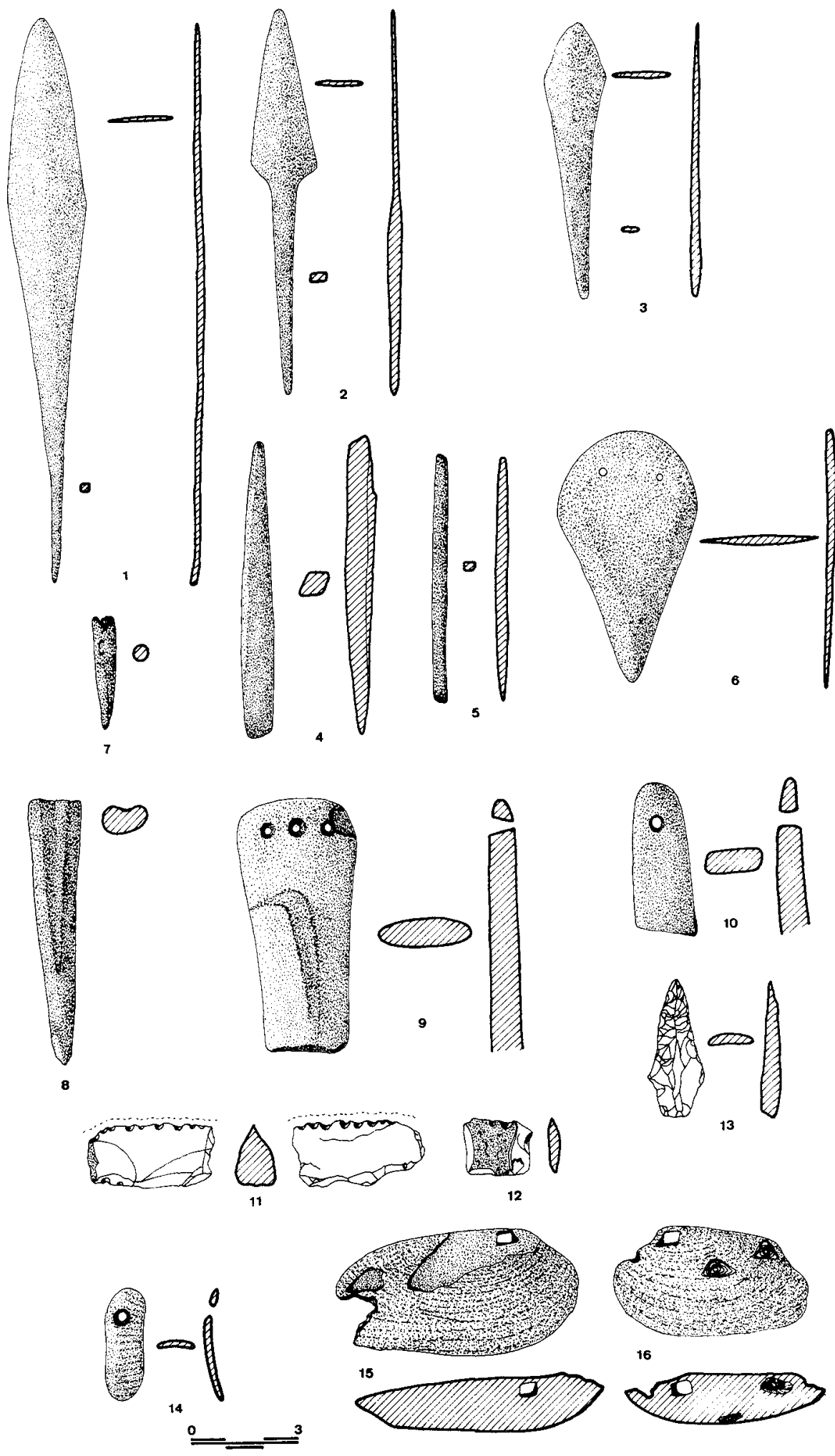

Figura 19.-Mina de Don Ricardo. 1-6: metal. 7-8: hueso. 9-13: lítico. 14-16: malacofauna. 
Vaso de borde recto, labio exvasado, cuerpo de casquete esferico. Superficies exterior e interior: espatuladas. Pasta y cocción: de buena calidad (fig. 18:8). N. ${ }^{\circ}$ de inventario: 77.

Vaso de borde recto, labio curvo, cuerpo semiesférico. Superficies exterior e interior: alisadas. Pasta y cocción: de buena calidad (fig. 18:9). N. ${ }^{\circ}$ de inventario: 76.

Vaso de borde entrante, labio curvo, cuerpo esférico. Superficies exterior e interior: espatuladas. Pasta y cocción: de buena calidad (fig. 18:10). N. ${ }^{\circ}$ de inventario: 39 .

Fragmento de quesera de borde recto, labio plano, cuerpo esférico. Superficies exterior e interior: alisado-espatuladas. Pasta y cocción: de buena calidad (fig. 18:11).

Fragmento de quesera de borde recto, labio curvo. Superficies exterior e interior: alisadoespatuladas. Pasta y cocción: de buena calidad (fig. 18:12).

Fragmento de pared decorada en ambas caras con incisiones, con pasta de mediocre calidad (fig. 18:13).

Se han inventariado, además, una decena de fragmentos cerámicos pertenecientes a vasos de similares características a los anteriores.

\section{Litico:}

Silex:

Diente de hoz de retoque continuo bifacial, sección triangular y lustre en ambas caras (fig. 19:11). N. ${ }^{\circ}$ de inventario: 1313.

Diente de hoz de retoque monofacial, sección ovalada y restos de cortex (fig. 19:12). N. ${ }^{\circ}$ de inventario: 1312.

Punta de flecha con las aletas indicadas y el pedúnculo fracturado, retoque bifacial y sección lenticular (fig. 19:13). N. ${ }^{\circ}$ de inventario: 8725 . Otros:

Fragmento de «brazalete de arquero» realizado en pizarra, sección oval, con tres perforaciones cónicas en un extremo y en línea (fig. 19:9).

Fragmento de colgante de forma ovalada, sección rectangular, con una perforación bitroncocónica (fig. 19:10). N. ${ }^{\circ}$ de inventario: 399.

Fragmento de piedra dura, de sección cuadrangular y pulidas todas sus caras.

Tres núcleos de cuarzo.
Óseo:

Fragmento de punzón sobre media caña de hueso largo, del que tan sólo se conserva el extremo distal apuntado (fig. 19:8). N. ${ }^{\circ}$ de inventario: 30 .

Fragmento distal de un punzón de sección circular (fig. 19:7). N. ${ }^{\circ}$ de inventario: 32.

\section{Metal:}

Punta de jabalina, de sección ovalada. Dimensiones: Largo: 15,4 , ancho: 2,1 y grosor: 0,2 . Peso: 17,1 gr. (fig. 19:1).

Punta de flecha de pedúnculo. Dimensiones: $10,5 \mathrm{~cm}$. de largo, $1,8 \mathrm{~cm}$. de ancho y 0,2 de grosor en la hoja y 0,4 en el pedúnculo. Peso: 10,2 gr. (fig. 19:2).

Punta de flecha del tipo de Palmela, con hoja algo erosionada y sección ovalada a lo largo de toda la pieza. Dimensiones 7,5 cm. de largo, 1,67 cm. de ancho y 0,3 de grosor. Peso: 6.2 gr. (fig. 19:3).

Cincel de sección rombotrapezoidal. Dimensiones: $8,1 \mathrm{~cm}$. de largo, $0,7 \mathrm{~cm}$. de ancho y $0,6 \mathrm{~cm}$. de grosor. Peso: 23,8 gr. (fig. 19:4).

Cincel de sección cuadrangular. Dimensiones: $6,8 \mathrm{~cm}$. de largo, $0,4 \mathrm{~cm}$. de ancho y $0,3 \mathrm{~cm}$. de grosor. Peso: 5,3 gr. (fig. 19:5).

Puñal de remaches del Tipo II de B. Blance, con dos perforaciones en línea y sin los remaches. Dimensiones: $6,8 \mathrm{~cm}$. de largo, $3,8 \mathrm{~cm}$. de ancho y $0,2 \mathrm{~cm}$. de grosor. Peso: 17,4 gr. (fig. 19:6).

Escoria de fundición de $44,2 \mathrm{gr}$. de peso. N. ${ }^{\circ}$ de inventario: 1324 .

\section{Fauna:}

Se han inventariado dos cuernos de cabra y un cuerno de corzo.

\section{Malacología:}

Colgante de forma ovalada realizado en valva de pectúnculo con una perforación bicónica (fig. 19:14).

Colgante realizado en concha con perforación cuadrangular (fig. 19:15).

Colgante realizado en concha con perforación cuadrangular y con señales de otras perforaciones circulares (fig. 19:16).

\section{III.4. Interpretación de los datos de la excavación:}

No se posee ningún dato sobre la excavación ni de la procedencia de los materiales, por lo que 
sólo podemos valorar el yacimiento a partir de nuestras propias observaciones. Se trata de una estructura artificial ovalada de apenas $3 \mathrm{~m}$. de altura sobre la ladera basculada de NE a SW. La expoliación se realizó sobre todo en la parte central, deformando totalmente el yacimiento, en donde se encuentra la entrada de una cueva natural, hoy cegada, pero por noticias de vecinos de Tiriez es de gran longitud y amplitud, con una gran galería alargada que le da un aspecto similar a los «minados» artificiales. En esta cueva, de grandes dimensiones, aflora en varios puntos el nivel freático.

Las estructuras exteriores están muy deterioradas pero parecen reflejar plantas ovales y concéntricas tomando como punto central la entrada de la cueva. También podría tratarse de dos estructuras de las mismas características unidas por dos muros paralelos y quedando la cueva entre ambas y los muros.

El espacio circundante se encuentra labrado y no se aprecian restos arqueológicos.

\section{III.5. Bibliografía específica del yacimiento:}

SÁNCHEZ JIMÉNEZ, J. 1948: «La cultura del Argar en la provincia de Albacete» III C.A.S.E. Murcia 1947. Cartagena, 73-79.

SÁNCHEZ JIMÉNEZ, J. 1948: «La cultura algárica en Albacete. Notas para su estudio» $A . y$ M. S.E.A.E. y P. t. XXIII, c. 1-3. Madrid, 96-110.

SÁNCHEZ JIMÉNEZ, J. 1947: Excavaciones y trabajos arqueologicos en la provincia de Albacete de 1942 a 1946. Informes y Memorias N. ${ }^{\circ} 15$. 63. Madrid.

\section{CONSIDERACIONES FINALES:}

El estudio de estos tres yacimientos nos permite una mayor aproximación al conocimiento de la Edad del Bronce en Albacete, a la cual se le han supuesto afinidades culturales con otras áreas peninsulares sin base consistente.

Para paralelizar los conjuntos cerámicos de los yacimientos aquí estudiados nos basaremos en yacimientos cercanos con memorias de excavación o avances publicados. Cerámicas fechadas sólo las encontramos en el Cabezo Redondo (Villena, Alicante) y en el Cerro de la Campana (Yecla, Murcia), y un tanto más alejados en la Morra de Quin- tanar (Munera, Albacete), el Cerro de la Encantada (Granatula de Calatrava, Ciudad Real) y las Motillas de Azuer y Palacios (Daimiel, Ciudad Real).

La escasez de los materiales del Cerro de la Campana nos hace descartarlo para paralelizarlo con las piezas estudiadas. En el Cabezo Redondo, en cambio, existe un amplio registro, pero nos tenemos que limitar a los vasos con peculiaridades claras pues los de forma simple poseen una amplia cronología, aunque pueden servir para la valoración de conjuntos.

Los materiales procedentes de la Excavación del Cerrico Redondo (Montealegre del Castillo) se pueden dividir en tres conjuntos: el ceramológico, metálicos o metalúrgicos y varios.

El conjunto cerámico parece que pertenece todo a una misma habitación por lo que cronológicamente son del mismo momento.

Similares características al vaso de la fig. 4:4 las encontramos en los Departamentos VIII y XV, este último fechado en el $1370 \pm 55$, del Cabezo Redondo (SOLER, 1986, 400) y formando parte de un ajuar funerario del Bronce Medio en el Cerro de la Encantada (NIETO y MESEGUER, 1980, fig. 36).

El vaso de la fig. 4:8 tiene paralelos en el Departamento XIII del Cabezo Redondo (SOLER, 1987, fig. 93:3), aunque sin las asas y el cuerpo más ancho.

Paralelos para el vaso de la fig. 6:5, pequeño cuenco con ónfalo, los encontramos en el Departamento XVIII del Cabezo Redondo (SOLER, 1987, 104:4 y 106:4), en la Fuensanta (Almansa) (SIMÓN, 1987, fig. 18:7) y en vaso carenado en el Cerro de la Encantada (NIETO y MESEGUER, 1980, fig. 59: B).

El resto de los vasos, con alguna excepción como la fig. 4:9, y el conjunto en general poseen similares características a las del registro cerámico del Cabezo Redondo, sobre todo en sus departamentos I, III, V, VI, XIII, XV y XVIII y a las características generales de los poblados del Corredor de Almasa.

El conjunto metálico-metalúrgico lo componen un crisol (fig. 6:10), un molde de varilla y una sierra (fig. 6:9). Del primer objeto en la provincia de Albacete sólo se han publicado de unos fragmentos en la morra del Quintanar (MORALES, 1984, pág. 71) y en el Cerro Almorchón (DE LA TORRE, 1932, 19).

Moldes similares al aquí tratado (fig. 6:8) se han inventariado en la provincia de Albacete en el Cerro 
el Púlpito (SIMÓN, 1984, fig. 6:1) en la Morra del Quintanar de la Munera (inédito, expuesto en la Vitrina N. ${ }^{\circ} 6$ de la Sala de la Edad del Bronce del Museo Provincial de Albacete) y otro estudiado en este mismo trabajo procedente de La Peñuela II (fig. 15:3).

Hasta el momento la presencia de sierras es inédita en la provincia de Albacete (fig. 6:9), sin embargo, las encontramos en las provincias de Alicante (SIMÓN, en prensa), Murcia (AYALA JUAN, 1981 y 1986), Almería (SIRET, L. y E. 1890), etc, en yacimientos argáricos.

Se han registrado otros objetos en el yacimiento, como un «pesa de telar» de barro de forma cuadrangular y con cuatro perforaciones (fig. 6:6) con paralelos en el Cerro del Cegarrón excavado por Zuazo Palacios y Obermaier donde también aparecieron pesar rectangulares con cuatro perforaciones, circulares con tres perforaciones y lenticulares con dos perforaciones. También las encontramos en la Morra del Quintanar (MARTÍN MORALES, 1984, 71).

De la expoliación de La Peñuela I sólo se recogieron aquellos materiales que se consideraron más atractivos. Se trata de piezas procedentes de niveles de habitación, no de ajuares funerarios. Se encontraron en lo más profundo de la cueva, si bien toda ella se encuentra sembrada de pequeños fragmentos cerámicos, no así las estructuras que circundan la estructura artificial.

El vaso carenado (fig. 13:1) posee unos claros paralelos, tanto por la forma como por el tamaño en la Morra del Quintanar (MARTíN MORALES, 1984, fig. 2), fechándose a finales del S. XVI y principios del S. XV a.C., y en la Motilla de Azuer, aunque con menor tamaño (NÁJERA y MOLINA, 1977, fig. 12:c). El vaso esférico (fig. 13:2) está presente en todos los círculos culturales, destacando la calidad de la pasta y el tratamiento de sus superficies.

El cucharón cerámico posee su paralelo más próximo en el Cabezo Redondo en el Departamento V (SOLER, 1987, 70:12), siguiendo por el Cabeço del Navarro o dels Alforins (ENGUIX, 1970, fig. 3:79) hacia el interior de las tierras del País Valenciano.

El material óseo se compone de un gran punzón (fig. 13:7) de amplios paralelos y una punta de flecha (fig. 13:6). Fue estudiada por W. Pape (1982, 137-139) e incluida en su grupo $A$, con una fecha- ción paralelizada con otras peninsulares en el Bronce Antiguo y Medio. Recientemente publicadas se han inventariado otras en el Cabezo Redondo (SOLER, 1987, fig. 45) y concretamente una de similares características aunque con el pedúnculo más corto (SOLER, 1987, fig. 45:5).

En metal se registra un puñal (fig. 13:4) del Tipo III de B. Blance que tradicionalmente se le da una cronología a caballo entre el Argar A y B. Sus paralelos más cercanos los encontramos en El Amarejo (BRONCANO, 1984, 83) donde existe un puñal del mismo tipo pero con tan sólo dos remaches, en la Morra de la Cueva de la Paja (SIMÓN, inédito), procedente de un contexto funerario, y en el Cabezo Redondo (SOLER, 1987, fig. 48:14), este último de similares características al de El Amarejo.

La punta de flecha (fig. 13:5) de pedúnculo y aletas es un objeto típico de poblado, relacionado con actividades cinegéticas o bélicas. Por su forma sólo posee por el momento paralelos en Albacete en otra pieza aquí estudiada (fig. 19:2) procedente de la Mina de D. Ricardo. Fuera de Albacete encontramos de aproximadas características una en la Motilla de Azuer (NÁJERA y MOLINA, 1977, fig. 12:j), y en mayor número en Murcia y Almería.

Los materiales de La Peñuela II proceden de la cueva y de la estructura que la rodea. De la primera procede un gran vaso decorado con mamelones y cordones (fig. 14:1) que no posee paralelo alguno por el momento en la provincia de Albacete ni áreas colindantes. El uso frecuente de cordones para decorar el vaso lo encontramos sobre todo al $\mathrm{N}$ del Júcar, centrándose en Castellón y el uso de mamelones situados por todo el vaso, bien en fila o dispersos lo encontramos los primeros en el Cabezo Redondo (SOLER, 1987, fig. 113), en La Horna (HERNÁNDEZ, 1986, fig. 3) y en el Picacho (HERNÁNDEZ HERNÁNDEZ y DUG GODOY, 1977, 56) en donde aparece la asociación de cordones y mamelones. En todos los casos se fechan en momentos finales del Bronce Medio o principios del Bronce Tardío. Junto a él se localizó otro vaso de forma, tratamientos y asas de amplios paralelos.

Los vasos aparecidos en la estructura artificial (fig. 14:3-10; 15:1) son de formas simples por lo que sus paralelos son amplísimos, viéndose acompañados por un fragmento de cucharón (fig. 15:2) con paralelos ya señalados anteriormente.

El material óseo se limita a una serie de punzones (fig. 15:5-9) de variada tipología y amplios 
paralelos. En el utillaje lítico sólo se inventarió un extremo de un cuchillito de silex de amplia perduración cronológica y un molde de fundición de varilla con las mismas características, por lo tanto con los mismos paralelos, que el del Cerrico Redondo.

En la Mina de D. Ricardo el material cerámico se divide en grandes vasijas de almacenamiento (fig. 17), uno de los cuales pertenece a la forma 5 de Siret y posee unos paralelos con similar tamaño en la Morra del Quintanar (MARTÍN MORALES, 1984, fig. 2), y en una serie de pequeños vasos, unos de gran calidad técnica y pertenecientes a la forma 5 de Siret (fig. 18:1-6), los cuales en cuatro ocasiones (fig. 18: 1-3 y 6) poseen una carena baja, dos de las cuales se encuentran decorados con pequeños mamelones (fig. 18:1.3) y otro cuatro perforaciones (fig. 18:5). Sus paralelos los encontramos en el Cerro de la Encantada (NIETO y MESEGUER, 1980), aunque en este caso formando parte de ajuares funerarios y en la Motilla de Azuer (NÁJERA y MOLINA, 1977, fig. 12:c).

El segundo subgrupo lo componen dos vasos esféricos de borde entrante de cronología generalmente antigua (fig. 18: 7 y 10), uno de casquete esférico (fig. 18:8), otro semiesférico (fig. 15:9), dos fragmentos de quesera con paralelos en la provincia de Albacete en la Morra del Quintanar (MARTÍN MORALES, 1984, 71), en Toriles en Fuente Alamo (SIMÓN, inédito), etc. y un fragmento de cerámica decorada con incisiones en ambas caras ya tratado por C. Martín Morales $(1984,72)$, con paralelos en la Morra del Quintanar y en la Motilla de Sta. M. ${ }^{a}$ del Guadiana (NÁJERA y MOLINA, 1977, 275) e incluido en un Bronce Antiguo.

El material lítico se reduce a un fragmento de un «brazalete de arquero» (fig. 19:9) con tres perforaciones, por lo que podría tratarse de un elemento de adorno, con paralelos en el Amarejo (BRONCANO, 1984, 83) y una cronología amplia, dos dientes de hoz (fig. 19:11-12), también de amplia cronología, una punta de flecha de pedúnculo y aletas indicadas (fig. 19:13) con paralelos en el Amarejo (BRONCANO, 1984, 83) y en el Cerrico de la Be (SIMÓN, 1987, fig. 18:4) con una cronología por lo general antigua dentro del II milenio, y un fragmento de un colgante en piedra (fig. 19:10) que recuerda a otros sobre caparazones de moluscos.

El conjunto metálico no posee paralelos ni en la provincia ni en las áreas próximas y está com- puesto de una punta de jabalina (fig. 19:1), con una forma próxima a las puntas de Palmela, éstas con una amplísima cronología, una punta de flecha con pedúnculo y aletas (fig. 19:2) con paralelos provinciales tan sólo en La Peñuela I, una punta de Palmela (fig. 19:3) con paralelos en el Cerro el Púlpito (SIMÓN, 1987, fig. 8:15), dos cinceles con un único paralelo en un fragmento del 2. ${ }^{\circ}$ Puntal del Mugrón (SIMÓN, 1987, 98) y en el Cabezo Redondo (SOLER, 1987, fig. 47:3-7), con cronología sin determinar y un puñal (fig. 16:6) del Tipo II de B. Blance con paralelos en el Cabezo A (SIMÓN, 1987, fig. 9:2), en el Túmulo II de Torcino, en el Cerro del Aquililla en Casas Ibáñez, en la Casa de los Arbones, etc., con fechaciones antiguas en el SE.

El Cerrico Redondo es un yacimiento típico de la zona oriental de la provincia, encuadrable en el Tipo I de los yacimientos estudiados en el Corredor de Almansa, aunque en esta zona poseen unos porcentajes menores. Se sitúa en la parte occidental del pequeño valle que une las tierras del Altiplano de Yecla-Jumilla con el Altiplano de Montearagón y el Corredor de Almansa. Pese al movimiento de grupos humanos que posiblemente circulasen por la zona existe una total despreocupación por la defensa, no sólo por la inexistencia de murallas sino también por la elección del hábitat, en un cerro de escasa altura sobre el llano que en la ladera septentrional apenas si se diferencia de las lomas que delimitan al valle.

La estructura excavada apunta hacia una gran cabaña de planta rectangular, de grandes dimensiones, con una puerta con un vano muy amplio y paradójicamente orientado al N. Estaba constituida por un zócalo de piedra de aproximadamente unos 80 $\mathrm{cm}$. de altura, siendo el resto, paredes y techo de barro con material vegetal, el cual se encuentra en la actualidad disperso por las laderas. Se aprecian en el cerro otros restos de construcciones, aunque estas debieron de ser de similares características.

El conjunto cerámico encontrado es muy simolar en formas, tratamientos y calidad al del Cabezo Redondo de Villena, sobre todo en los fechados a mediados del S. XIV a. C., por lo que nos inclinamos hacia una fuerte influencia cultural del Valle del Vinalopó. Esta influencia podría explicar en parte la presencia de actividades de transformación metalúrgica local que suponemos a pequeña escala y autoabastecedora de ciertas piezas simples, la cual pudo suministrarse de mineral en lingotes o verse obligada a refundir piezas, como lo apunta unas 
láminas en proceso de transformación, y la presencia de una sierra con paralelos en el SE y parte del País Valenciano. Sin embargo, la principal actividad del poblado debió ser la agrícola, ya que aparecieron varios vasos llenos de cereal, sobre todo trigo, aprovechando la cercanía y abundancia de tierras cultivables. Por el contrario la excavación proporcionó una gran escasez de fauna.

Las Peñuelas I y II se encuentran en el centro de la provincia, sobre un cerro situado en los llanos de Chinchilla-Albacete. Por sus características deben relacionarse con la Cultura de las Motillas, definida en yacimientos de Ciudad Real, por poseer una estructura constructiva similar, es decir, un muro circular central rodeado de otros concéntricos. No obstante, las aquí tratadas presentan notables diferencias, ya que no se ubican en llanos ni cerca de cuencas fluviales ni cubetas endorreicas, sino en la ladera o en la parte alta del cerro o lomas, ambas sobre cuevas naturales y con un tamaño mucho menor. En estos dos yacimientos la cueva forma parte del propio hábitat. Del mismo modo las estructuras circundantes a Las Peñuelas parecen no pertenecer a cabañas, ya que sólo se conserva un zócalo de pequeñas dimensiones y la excavación de parte de una de ellas así lo reveló.

Los materiales que se recogieron en Las Peñuelas pertenecen claramente a niveles de poblado $\mathrm{y}$ nada tienen que ver con ajuares funerarios, no constatados en el yacimiento. En La Peñuela I los materiales nos dan una diversidad de datos cronológicos y culturales, así mientras la punta de flecha de hueso se encuentra fechada en un Bronce Antiguo, el puñal lo es en el tránsito del Bronce Antiguo al Medio y con paralelos en el SE, y en el cucharón posee el mayor número de paralelos en el País Valenciano. En la Peñuela II en el gran vaso decorado con cordones y mamelones apunta hacia momentos del Bronce Tardío, con paralelos en Castellón y en el SE. En ambos yacimientos la industria ósea es abundante y de elevada calidad técnica. En la Peñuela II se inventarió un molde de fundición que atestigua, al igual que en el Cerrico Redondo, una metalurgia a pequeña escala de ámbito local.

La Mina de D. Ricardo se sitúa en la margen derecha del Río Lezuza, pero a media altura de la vertiente meridional de un cerro y sobre una gran cueva natural, es decir, con las mismas características que las Peñuelas y por tanto con las mismas diferencias y similitudes con las motillas de Ciudad Real. Aquí la estructura es oval, la cueva de mayores dimensiones y los materiales similares a los procedentes del Cerro de la Encantada en Ciudad Real. El conjunto lítico, óseo y malacológico es variado y muy posiblemente procedentes de niveles de habitación. Pero es el conjunto metálico lo más destacable, por su número y calidad, no sólo en el yacimiento sino en la provincia. Está compuesto por objetos de uso cotidiano, bien para actividades cinegéticas o bélicas, como la punta de jabalina o las puntas de flecha, para la elaboración de objetos, como los cinceles, o de uso cotidiano, como el puñal. El conjunto no aporta datos cronológicos pero apunta hacia un desarrollo de la metalurgia local o a la existencia de inmejorables vías comerciales.

En este yacimiento se dan una serie de objetos que apuntan a perduraciones de momentos anteriores, como la punta de flecha de silex, un fragmento decorado con incisiones y una punta de metal del tipo de Palmela.

Estos tres últimos yacimientos junto con la Fuensanta de Almansa ya estudiada en un trabajo anterior, forman un grupo de yacimientos próximos a las motillas de Ciudad Real.

Los cuatro yacimientos se encuentran próximos a la misma latitud, dispuestos a una distancia lineal similar, todos con las mismas características, sobre todo el situarse sobre cuevas en las cuales aflora el nivel freático, por lo que el agua está asegurada en épocas de sequía. La interpretación con los datos que se poseen en la actualidad es difícil y arriesgada. Son asentamientos que están en función de la cueva e indirectamente del agua que en ella se encuentra. Pese a encontrarse en tierras muy aptas para la agricultura no aparecen útiles relacionados con ella, como dientes de hoz, molinos, morteros, etc., y sí relacionados con la ganadería, como una industria ósea muy desarrollada, encellas o queseras, etc., o con la caza, puntas de jabalina, flecha, etc. Quizás nos encontremos ante grupos humanos con una actividad económica preferentemente ganadera, con desplazamientos anuales buscando los pastos más adecuados según las épocas del año, desde las zonas húmedas de la parte occidental de la provincia hasta otras de una climatología más suave durante el invierno en la parte oriental, y con una serie de establecimientos temporales y equidistantes que aseguren el abastecimiento de agua en períodos de largas sequías. Estos grupos pudieron utilizar estos asentamientos temporales durante un amplio período, ya que aparecen objetos que van desde un momento inicial del Bronce Antiguo con tradición eneolítica 
hasta momentos del Bronce Tardío. Sus movimientos explicarían las diversas influencias de los diferentes grupos culturales patentes en los paralelos de objetos muebles.

Nos encontramos con un hábitat muy variado en la Edad del Bronce en la provincia de Albacete, en cerros más o menos encastillados como el Cerrico Redondo, en motillas como el Acequión, en motillas albaceteñas como Las Peñuelas, la Mina de D. Ricardo y La Fuensanta, en semillanura o en la ladera suave de una loma como el Cerro de la Casa Nueva en Pétrola y muy posiblemente en llanura.

Los datos obtenidos del Cerrico Redondo, La Peñuela II, la Morra del Quintanar y el Cerro Almorchón parecen apuntar hacia una metalurgia de objetos simples, como punzones, cinceles, etc., en la mayoría de los poblados de la provincia de Albacete, transformando mayoritariamente chatarra.

La investigación sobre la Edad del Bronce en Albacete se encuentra en pleno desarrollo y la publicación de las memorias de excavación permitirán un mayor conocimiento del período y de las circunstancias que lo rodean. Nosotros hemos pretendido una ordenación y una aproximación a su interpretación de los fondos antiguos del Museo Provincial de Albacete, partiendo de los datos aportados por la investigación en la última década, trabajo en el cual seguimos investigando.

\section{BIBLIOGRAFÍA}

AGUADO Y SÁEZ, L. 1979: «La motilla de Azuer (Daimiel, Ciudad Real) Campaña 1976», N.A.H. VI 21-50.

APARICIO PÉREZ, J. 1976: Estudio Económico y Social de la Edad del Bronce Valenciano. Valencia.

ARRIBAS PALAU, A. 1959: «EI urbanismo durante el Bronce primitivo». Zephyrus, 10. 81-128.

ARRIBAS, A. et alii 1974: «Excavaciones en el poblado de la Edad del Bronce "Cerro de la Encina" (Monachil, Granada). El corte estratigráfico n. ${ }^{\circ} 3 » . E . A . E .81$.

ATRIAN JORDÁN, P. 1974: «Un yacimiento de la Edad del Bronce en Frías de Albarracín (Teruel) 52. 7-32.

AYALA JUAN, M. M. 1981: «La Cultura del Argar en la provincia de Murcia». Anales de la Universidad de Murcia. Filosofía y Letras, 147-194.

- 1986: «El poblamiento Argárico». Historia de Cartagena 253-316.

BERNABEU AUBIÁN, J. 1986: «El Eneolítico Valenciano ¿Horizonte cultural o cronológico?, El Eneolítico en el País Valenciano. 9-14.

BLANCE, B. 1971: Die Anfänge der Metallurgie auf der Iberischen Halbinsel». Studien zu den Anfänge der Metallurgie. Berlín.
BLANCO DE LA RUBIA, I. 1983: «El Castillejo de Acebuchal. Un yacimiento de la Edad del Bronce (Pozuelo de Calatrava, Ciudad Real)». C.N.A. XVI, 359-370.

BRONCANO, S. 1984: «El poblado ibérico de "El Amarejo" (Bonete-Albacete)», Al Basit 15, 75-108.

CUADRADO, E. 1950: «Ưtiles y armas de El Argar. Ensayo de tipología». $1 .{ }^{\circ}$ Congreso de Arqueología y $V$ del Sudeste (Almería 1949). 103-122.

DE LA TORRE PARRAS, S. 1932: «El cerro del Almorchón en las lagunas de Ruideran. Boletín de la Comisión Provincial de Monumentos Históricos y Artísticos de Albacete. 17-19.

GARCÍA LÓPEZ e IDÁÑEZ SÁNCHEZ, 1984: «Poblados de la Edad del Bronce en la Sierra del Pino, Hellín (Albacete)». $1 .^{\circ}$ Congreso de Historia de Albacete 117-138.

GARCÍA SOLANA, E. 1966: "Yacimientos arqueológicos de Munera (Albacete) y sus aledaños, Saetabi XVI, 77 y ss.

GIL MASCARELL, M. 1981: «El Bronce Tardio y Final en el País Valenciano». Monografías del Laboratorio de Arqueología de Valencia, Valencia, 13.

- 1985: «El Final de la Edad del Bronce». Arqueología en el País Valenciano: panorama y perspectivas, 141-152.

GONZÁLEZ PRAT, A. 1986: «Pic de les Moreres». Arqueología en Alicante 1976-1986, 125.

ENGUIX ALEMANY, R. 1981: «Tipología de la cerámica de la cultura del Bronce valenciano». Saguntum 16, 63-74.

- 1982: «La Edad del Bronce» Nuestra Historia T. 1, 151-172.

HARRISON, R. J. 1977: «The Bell Beacher Cultures of Spain and Portugal». Amer. Scholl of Preh. Research. Massachussetts.

HERNÁNDEZ PÉREZ, M. S. 1985: «La Edad del Bronce en el País Valenciano». Arqueologia del País Valenciano: panorama y perspectivas, 101-120.

- 1986: «La Cultura de El Argar en Alicante. Relaciones temporales y espaciales con el mundo del Bronce Valenciano». Homenaje a Luis Siret (934-1984), 341-350.

HERVAS y BUENDÍA, 1899: La Motilla de Torralba. Mondoñedo.

LERMA, V. 1981: «Orígenes de la metalurgia en el País Valenciano». A. P. L. 16. 129-140.

LULL, V. 1983: La Cultura del Argar, Madrid.

LLOBREGAT CONESA, E. 1966: «Avance a una clasificación tipológica de las cerámicas del Bronce Valenciano: la colección del Museo Arqueológico Provincial de Alicante», $C$. N. A. IX, 129-134.

- 1969: «El poblado de la Cultura del Bronce Valenciano de la Serra Grossa, Alicante». Papeles del Laboratorio de Arqueología de Valencia, 6, 31-70.

- 1975: «Nuevos enfoques para el estudio del período del Neolítico al Hierro en la región valenciana». P. L.A. V. 119 140. II.

MARTÍ OLIVER, B. 1983: El nacimiento de la agricultura en el País Valenciano. Del Neolitico a la Edad del Bronce. Valencia.

MARTÍN MORALES, C. 1983: «Las fechas del Quintanar (Munera, Albacete) y la cronologia absoluta de la Meseta Sur». Homenaje a Martín Almagro, T. II, 23-57.

- 1984: «La Morra del Quintanar (Munera, Albacete). Al Basit 15, 57-73.

MOLINA, F. y PAREJA, E. 1975: Excavaciones en la Cuesta del Negro (Purullena, Granada), Campaña 1971, E. A. E. 86.

MOLINA, F. 1978: «Definición y sistematización del Bronce Tardio y Final en el Sudeste de la Península». Cuadernos de Prehistoria de la Universidad de Granada 3, 159-232.

MOLINA GRANDE, M. y MOLINA GARCÍA, J. 1979: Carta arqueológica de Jumilla. Murcia. 
MOLINA, J. 1986: «La Expansión Argárica hacia el País Valenciano a través del Altiplano Jumilla-Yecla, Homenaje a Luis Siret 1934-1984. 405-417.

MUÑOZ AMILIBIA, A. M. 1986: «EI Eneolítico en el Sureste». Historia de Cartagena, 143-162.

NÁJERA, T. y MOLINA, F. 1977: «La Edad del Bronce en la Mancha, Excavaciones en la Motilla de Azuer y los Palacios (Campaña de 1974)». Cuadernos de Prehistoria de la Universidad de Granada, 2, 251-300.

NÁJERA, T. et alii, 1977: «Excavaciones en la Motilla de Azuer y los Palacios (Ciudad Real)», C. N. A. XVI 503-514.

NÁJERA, T., MOLINA, F. y AGUADO, P. 1979: «La Motilla de Azuer (Daimiel, Ciudad Real)», Cuadernos de Prehistoria de la Universidad de Granada 4, 265-294.

NAVARRO MEDEROS, J. F. 1982: «Materiales para el estudio de la Edad del Bronce en el Valle Medio del Vinalopó» Lucentum I, 19-70.

NIETO GALLO, G. y CLEMENTE MARTÍN, J. 1983: «El Cerro de la Campana y su cronología según el C-14 (YeclaMurcia)»C. N. A. XV, 295-308.

NIETO G. y SÁNCHEZ MESEGUER, J. 1980: «El Cerro de la Encantada. Granatula de Calatrava. Ciudad Real», E. A. E. 113.

NIETO GALLO, G. et alii 1983: «El Cerro de la Encantada. Campaña 1979». N. A. H. 7-42.

PELLÓN GONZÁLEZ, J. 1984: «El Cerro Pelado, Cenizate (Albacete) $) .1 .^{\circ}$ Congreso de Historia de Albacete 107-116.

RODANES VICENTE, J. M. ${ }^{a}$ 1987: La industria ósea prehistórica en el Valle del Ebro. Zaragoza.

PAPE, W. 1982: «Au sujet de quelques pointes de flèches en os». Industrie de l'os neolithique et de l'age des metaux 2, 135-172.

ROS SALA, M. M. 1986: «El Bronce Tardío y Final». Historia de Cartagena, 319-352.

RUIZ-GÁLVEZ, M. 1977: «Nueva aportación al conocimiento de la Cultura del Argar». T. P. 34, 85-104.

SÁNCHEZ GÓMEZ, J. 1984: «Panorama arqueológico de Socovos». 1. ${ }^{\circ}$ Congreso de Historia de Albacete 341-375.

SÁNCHEZ MESEGUER et alii, 1983: «El Oficio y La Encantada: dos ejemplos de culto en la Edad del Bronce en la Península Ibérica» C. N. A. XVI 383-396.
SÁNCHEZ JIMÉNEZ, J. 1941: «Unna cineraria del Túmulo II de La Peñuela (Pozo Cañada, Albacete)», Actas y Memorias de la S. E. A. E. P. t. XVI, cuadernos I y II. 161-163.

- 1947: Excavaciones y trabajos arqueológicos en la provincia de Albacete de 1942 a 1946. Informes y Memorias n. ${ }^{\circ} 15$.

- 1948: «La cultura del Argar en la provincia de Albacete» III C. A. S. E. Murcia 1947, 73-79.

- 1948: «La cultura algárica en Albacete. Notas para su estudio». A. y M. S. E. A. E. y P. t. XXIII, c. 1-3. 96-110.

SANGMEISTER, SCHRÖDER, JUNGHANS, 1960: Metallanalysen Kupferzeitlicher und Frühbronzezeitlicher Bodenfunde aus Europa. Berlin.

SCHUBART, H. 1975: «Cronología relativa de la cerámica sepulcral en la Cultura de El Argar». Trabajos de Prehistoria 32, 79-92.

- 1975: «Relaciones mediterráneas de la cultura de El Argar». Zephyrus XXVI-XXVII.

- 1975: Die Kultur der Bronzezeit in Südwesten der Iberischen Halbinsel, Berlín.

- 1986: «Consideraciones sobre el Bronce del Sureste Peninsular». Historia de Cartagena, 217-250.

SIMÓN GARCÍA, J. L. 1984: «Contribución al estudio de la Edad del Bronce en Almansa» $1 .{ }^{a}$ Jornadas de Historia de Albacete. 777-85.

- 1987: La Edad del Bronce en Almansa, Albacete.

SIRET, H. y L. I890: Las primeras edades del metal en el sudeste de España. Barcelona.

SOLER GARCÍA, J. M. 1986: «La Edad del Bronce en la comarca de Villena». Homenaje a Luis Siret 1934-1984. 381-404.

- 1987: Excavaciones Arqueológicas en el Cabezo Redondo. (Villena-Alicante). Alicante.

SORIANO SÁNCHEZ, R. 1984: «La Cultura del Argar en la Vega Baja del Segura». Saguntum, 18. 103-143.

TARRADELL, M. 1965: «El problema de las diversas áreas culturales de la Península en la Edad del Bronce». Miscelánea al Abate H. Breuil (1877-1961). t. II, 423-429.

ZUAZO PALACIOS, J. 1915: Montealegre del Castillo y su Cerro de los Santos. Madrid.

- 1916: Meca. Contribución al estudio de las ciudades ibéricas. Madrid. 